
OF TECHNOLOGY

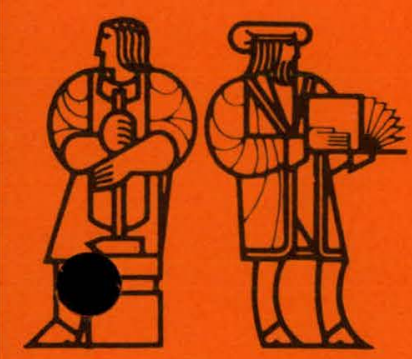




\section{DISCLAIMER}

This report was prepared as an account of work sponsored by an agency of the United States Government. Neither the United States Government nor any agency Thereof, nor any of their employees, makes any warranty, express or implied, or assumes any legal liability or responsibility for the accuracy, completeness, or usefulness of any information, apparatus, product, or process disclosed, or represents that its use would not infringe privately owned rights. Reference herein to any specific commercial product, process, or service by trade name, trademark, manufacturer, or otherwise does not necessarily constitute or imply its endorsement, recommendation, or favoring by the United States Government or any agency thereof. The views and opinions of authors expressed herein do not necessarily state or reflect those of the United States Government or any agency thereof. 


\section{DISCLAIMER}

Portions of this document may be illegible in electronic image products. Images are produced from the best available original document. 


$$
\text { MIT-EL- }-81-016
$$

DE82 013663

\title{
RECOMMENDATIONS CONCERNING ENERGY INFORMATION MODEL \\ DOCUMENTATION, PUBLIC ACCESS, AND EVALUATION
}

by

\author{
David 0. Wood \\ Martha J. Mason
}

October 1979

MIT Energy Laboratory Report \#MIT-EL 81-016 


\title{
Massachusetts Institute of Technology \\ Energy Laboratory \\ Energy Model Analysis Program
}

\section{Recommendations Concerning Energy-Information-Mode? Documentation, Public Access, and Evaluation \\ by}

David 0. Wood

Martha J. Mason

\begin{abstract}
Submitted to Office of Analysis Oversight \& Access

Office of Applied Analysis

Energy Information Administration

Department of Energy
\end{abstract}

October 1979

MIT Energy Laboratory Report \#MIT-EL 81-016

This research was supported by the Department of Energy under M.I.T. D.0.E. Institutional Agreement No. EX-76-A-07-2295. 
This report was prepared as an account of work sponsored by the Department of Energy. Neither the United States nor any agency thereof, nor any of their employees, makes any warranty, expressed or implied, or assumes any legal liability or responsibility for any third party's use or the results of such use of any information, apparatus, product, or process disclosed in this report, or represents that its use by such third party would not infringe privately owned rights. 


\section{Acknowledgments}

More than usual, this report bears the mark of many individuals who have provided information and the benefit of their own analysis and reflection. Most important are our colleagues in the M.I.T. Energy Model Analys is Program including Neil Goldman, Michael Manove, Ingo Vogelsang, Fred Schweppe, and especially James Gruhl who assisted in preparing Sections 3-2 and 3-3.

Within EIA and DOE the following individuals have been especially helpful: Denny Ellerman, Roger Glassey, Harvey Greenberg, George Lady, Elizabeth MacRae, Fred Murphy, Roger Naill, Richard 0'Neill, Dick Raemer, John Shewmaker, and Charles Smith.

Those in other government agencies who were interviewed include: Margaret Butler (Argonne, NESC), George Green (BEA), Albert Hirsch (BEA), Loren Kutscher (BLS), Marianne Legan (Argonne, NESC), Ron Mauri (DOT), Phil Ritz (BEA).

Finally, a number of others have contributed to this effort both through their research, and through informal discussion. They include: Martin Baughman (Texas), Saul Gass (Maryland), Martin Greenberger (Johns Hopkins), Bill Hogan (Harvard), Ric Jackson (NBS), Paul Joskow (MIT), Dilip Kamat (Texas), Rich Richels (EPRI), Hoff Stauffer (ICF, Inc.), Jim Sweeney (Stanford), Mike Wagner (ICF, Inc.), and John Weyant (Stanford). 
Table of Contents

Page

Executive Summary

1. Introduction and Sumary 6

2. Energy Information System Documentation, Public Access, and

Evaluation: Organization, Policies, and Plans

2.1 Background

2.2 Organizational Structure of the EIA 22

2.2.1 Applied Analysis 22

2.2.2 Information Validation 23

2.3 EIA Policies and Plans Relating to Energy System Documentation

2.3.1 Background $\quad 25$

2.3.2 Guidelines for Planning Policy Model Documentation

2.4 EIA Policies and Plans Relating to Public Access

2.5 PART Comments on EIA Documentation and Public Access Policies

3. Energy Model Evaluation 36

3.1 Elements of Policy Model Evaluation 41

3.2 Evaluation at Various Model Development Stages 43

3.2.1 Model Development Stages 44

3.2.2 Assessment at Development Stages 45

3.3 Implementation of Developmental Assessment 50

3.4 Survey of Model Evaluation Studies 58

Appendices

A Origins of Documentation and Public Access Requirements:

An Historical Analysis 
B A Review of Model Access Activities at Various Government Agencies

C A Survey of non-EIA Activities Relating to Policy Model Documentation, Access, and Evaluation 
EXECUTIVE SUMMARY

In this study we provide an analysis of the factors underlying Congressional concern regarding model documentation, policies for public access, and evaluation procedures of the Energy Information Administration (EIA) and its predecessor agencies; we also develop and present recommendations designed to improve current practice. This study reviews the history of Congressional concern; surveys current EIA organization and policies; provides an analysis of the model evaluation process; and presents recommendations to improve organizational efficiency and responsiveness, the model documentation process, public access policies, and model evaluation.

As a result of the reviews and analysis mentioned above, the following recommendations have been developed to improve the EIA procedures regarding model documentation, evaluation and access:

A. Organization of Energy Information System Documentation, Access, and Evaluation Functions

Recommendation 1: The separate missions of the Office of Analysis Oversight and Access and the Office of Validation Analysis should be clarified respecting their responsibilities for research on model analysis and evaluation, and the conduct of model evaluation projects.

Recommendation 2: The OAO\&A should designate a technical evaluation officer to parallel the activities and responsibilities of the technical project officer. The technical evaluation officer would participate in the documentation planning process, would plan, organize, implement the evaluation process, and would be responsible for implementing the access portion of the documentation plan (when relevant).

B. Documentation

Recommendation 3: The various memoranda and related materials which presently codify EIA policies regarding documentation guidelines and evaluation, public access, and model and model application evaluations should be collected and organized into a manual (or other suitable form) describing the responsibilities, authority, and operating procedures for the technical evaluation officer.

Recommendation 4: Each model development and model application project should include the preparation of a documentation $\mathrm{plan}$ as a joint responsibility of the technical project and evaluation officers. The documentation plan should include an analysis of the expected documentation needs reflecting the factors mentioned above, a disruption of the document types, an analysis of public access 
requirements and an access implementation plan. In general the depth of analysis and description should be sufficient to make clear the requirements, and the criteria for evaluating documentation performance.

Recommendation 5: The Monthly Energy Indicators should be expanded to include articles prepared primarily by EIA staff, surveying important data development, modeling, and model application efforts. As appropriate, articles discussing the highlights of mandated reports, such as the Administrator's Annual Report to Congress should be included.

C. Model Access and Archiving

Recommendation 6: More effort and encouragement should be given to submitting the results of EIA-sponsored research for publication in the relevant scientific literature. Such effort and encouragement should be reflected in the documentation planning process for important research and model development projects.

Recommendation 7: EIA should formally reconsider its program of archiving models and model-based applications at the Argonne National Energy Software System, either reemphasizing the importance of the program and devoting sufficient resources to ensure its success, or abolishing the program.

Recommendation 8: EIA should accept the Texas Energy and Natural Resources Advisory Council offer to transfer to Texas A\&M University the modeling system and associated data used in support of the Annual Report to Congress for use in supporting the TENRAC evaluation of the ARC, and for access by other competent users.

Recommendation 9: EIA should devote research and attention to developing "reduced-form models" of important EIA energy information systems, especially the systems employed in support of the Annual Administrator's Report to Congress.

Recommendation 10: The EIA should seriously consider augmenting its current public access policy by employing the EPRI/Stanford Energy Modeling Forum approach in organizing and conducting analys is of selected energy information issues.

D. Energy Model Analysis and Evaluation

Recommendation 11: Model evaluation should parallel model. development. The integrative analysis concerning objectives, approach, and organization of evaluation should be a primary... responsibility of the technical evaluation officer.

Recommendation 12: EIA should establish a simple set of guidelines or criteria to be met by any member of the public who wishes access to PIES (MEFS) in accordance with Section 31(3) of the ECPA of 1976. The fee to charge for such access and the possible provision of personnel to assist such users should be considered when drawing up the guidelines. 
INTRODUCTION AND SUMMARY

The rapid increase in the development and application of large-scale energy policy models since the 1973-74 OPEC oil embargo is unprecedented in the policy sciences. While other public policy areas, such as urban planning and water resources planning, have stimulated intensive modeling and model application efforts, energy policy modeling seems to be more visible and to have stimulated both the enthusiasm and concerns of broader constituencies. Visibility of energy policy modeling seems due to the pervasiveness of energy in society, the perceived urgency of energy issues, and to active programs in government, industry, foundations, and universities to develop and apply policy models in well publicized studies.* Such studies published in a form highlighting the role of energy policy models focus attention on models, sometimes at the expense of the analysis itself. The early identification of the FEA Project Independence Evaluation System (PIES) as the "pocket pistol of the President" gives some flavor of one type of concern about the role of models in the policy process.

While government and quasi-government model-based policy studies have contributed significantiy to model visibility, these applications have taken place in a broader context of scientific research and analysis of energy production and use. Prior to the embargo the NSF Research and Analysis for National Needs (RANN) program was sponsoring many energy related research projects, projects which were greatly stimulated by the focusing power of the embargo.** Subsequent to the embargo these modeling research activities were expanded with sponsorship from the DOE

*Examples include Federal Energy Administration (1974, 1976); Energy Research and Development Administration (1976); Energy Information Administration (1979); National Academy of Sciences (1979); Energy Policy Project of the Ford Foundation (1974); Nuclear Energy Policy Study Group (1977); Baughman and Joskow (1976), which analyzes the future of the nuclear power industry; Hudson and Jorgenson (1974), which analyzes the likely macro-economic and energy-sector efforts of al ternative energy tax policies; and the M.I.T. Policy Study Group (1974), which studies conditions for energy self-sufficiency.

** Much of the pre-embargo modeling effort is described and/or referenced in Macrak is (1974). 
predecessor agencies, and from EPRI, various foundations, and universities.

In addition to modeling research the policy interests of government and industry have stimulated the formation and/or expansion of commercial firms oriented toward providing model-based support for energy. policy evaluation and analysis. Al though generalizations are dangerous, as a rule these firms tended to organize and apply academic research results in modeling efforts and studies aimed at particular client groups and/or policy evaluation and analysis issues.*

This large investment in energy research and modeling has been based upon, and has stimulated, confidence that policy models can make a major contribution in energy policy evaluation and analysis. That the essence of a policy issue is that differences in policy turn on value conflicts between two or more constituencies in resolving factual or analytical disputes and/or in interpretation of expected consequences of implementing particular policies is generally recognized; but even when value conflicts dominate, model proponents argue that systematic analys is and presentation of the results of al ternative policies helps to make clear the nature and extent of the value conflict.

But while expectations are high, the actual success of model-based policy evaluation and analysis has not yet been widely demonstrated and accepted. The sources of disappointment are not readily classified, but seem mostly related to perceived failures in the models themselves and in the policy modeling process. Caricaturing somewhat: policy analysts tend to find models unfocused and lacking detail for the specific issues of interest, and difficult to "reconfigure" in a timely manner; further, assurances about the scientific validity of energy policy models have not been satisfactory. In contrast modelers are frustrated by the elusive and changing nature of the issues as posed by policy analysts, and sometimes even suspect the rationality of the policy process. Decision makers who rely on analysts as well as their various constituencies for inputs to policy making are confused and alarmed by conflicting analyses

\footnotetext{
* There are many examples. Particularly prominent would be Booz-Allen, Data Resources, Inc., Decision Focus, Inc., ICF, Inc., MITRE, Resource Planning Associates, and TRW.
} 
and are led to suspect the integrity of the modeling and analysis process. Finally the various constituencies potentially affected by model-based policy analysis seem suspicious that the modeling process may be indirectly resolving disputed factual, analytical, and value conflicts in a "black box" environment, especially when the model results are inconsistent with their policy positions.

Important initiatives to deal with these concerns include efforts to ensure congressional oversight of government energy modeling and data developinent, and government and industry efforts to better organize model-based policy research and to ensure scientific review and analysis of policy models, with results communicated in a form accessible to all groups interested in energy policy research. Within the federal government, the focus of these concerns and various efforts to improve the credibility of policy models and model-based applications has been the Energy Information Administraton (EIA) of the Department of Energy $(D O E)$. In response to legislative mandates and internal concerns that good management and scientific practices be followed, EIA has actively pursued policies to improve the documentation, public access, and scientific evaluation of its major energy information systems and model-based applications.

Summary

In this report for the Office of Analysis Oversight and Access (OAO\&A) Of EIA, we review the EIA response to Congressional and management concerns, relating specifically to energy information system documentation, public access to EIA systems, and scientific/peer evaluation. In the next section the relevant organizational and policy responses of EIA are discussed. In the following section an analysis of the model development process and approaches to, and organization of, model evaluation is presented. Included is a survey of model evaluation studies. A more detailed analysis of the origins of the legislated documentation and public access requirements is presented in Appendix $A$, and the results of an informal survey of other agency approaches to public access and evaluation is presented in Appendix B. Appendix C provides a survey of non-EIA activities relating to model documentation and evaluation. 
Based on our analysis we have twelve recommendations to improve EIA's procedures for energy information system documentation, evaluation activities, and public access.

A. Organization of Energy Information System Documentation, Access, and Evaluation Functions

The review of the EIA organization presented in Section 2 of this report has revealed that two organizational el ements have apparently overlapping responsibilities in the area of energy information systems and model validation. These are the Office of Analysis Oversight and Access under the Assistant Administrator for Applied Analysis, and the Office of Validation Analysis (in particular the Division of Energy Model Validation) under the Assistant Administrator for Energy Information Validation. The mission statements for these two elements are similar, suggesting potential for conflict. However, based on interviews with the relevant personnel, it is evident that no serious conflict is present. While OAO\&A has concentrated its efforts on procedures and evaluation for models developed under the authority of the Assistant Administrator for Applied Analysis, OVA has concentrated upon more general methodological issues. This fact could easily be reflected by appropriate revision to the Organization and Mission statement. Accordingly,

Recommendation 1: The separate missions of the Office of Analysis Oversight and Access and the Office of Validation Analys is should be clarified respecting their responsibilities for research on model analysis and evaluation, and the conduct of model evaluation projects.

A potentially more serious problem concerns the lack of complementarity between the model development and application process, and the process of planning, determining, and implementing appropriate forms of public access and evaluation. In summary, model development and model application projects are located within the relevant operating offices of the Office of Applied Analysis. The technical planning and supervision of projects is assigned to a technical project officer for projects implemented via contracts. For in-house efforts the project leader (usually occupying a management position) serves the function of the technical project officer. In either case the technical project officer has a span of authority, covering all technical aspects of project planning, implementation, and evaluation of and acceptance of 
final results.

In contrast, the OAO\&A has fragmented the span of authority for documentation planning and evaluation, dispersing access and model evaluation activities among separate staff. While not formally documented the process has been described to us as follows. At present, documentation planning consists of ensuring that the Interim

Documentation Standards are included with the Work Statements for all new projects. For documentation evaluation, contractors are being used with a representative of the OAO\&A serving as a technical project officer for the evaluation contract. All access plans are handled through a single individual, and currently involve only interaction with the National Energy Software System at Argonne. Model transfer requests, such as the Texas Energy and Natural Resources Advisory Council request, are handled primarily by the operating divisions. Finally, energy information system analysis and evaluation is conducted primarily through contracts, with an OAO\&A representative serving as technical project officer.

While this functional separation of the documentation planning and evaluation, access, and evaluation tasks has some merits, especially in the early stages of OAO\&A operations, inefficiencies are likely to occur because of the lack of complementarity between organization of the OAO\&A activities and the model development and model-based application process. Accordingly,

Recommendation 2: The OAO\&A should designate a technical evaluation officer to parallel the activities and responsibilities of the technical project officer. The technical evaluation officer would participate in the documentation planning process, would plan, organize, implement the evaluation process, and would be responsible for implementing the access portion of the documentation plan (when relevant).

As a related matter, it will be necessary to codify the responsibilities, authority, and operating procedures for the technical evaluation officer. Accordingly,

Recommendation 3: The various memoranda and related materials which presently codify EIA policies regarding documentation guidelines and evaluation, public access, and model and model application evaluations should be collected and organized into a manual (or other suitable form) describing the responsibilities, authority, and operating procedures for the technical evaluation officer. 
B. Documentation

The EIA has promul gated interim documentation standards, and currently has under review a proposal for more detailed standards. These standards provide a useful checklist of documentation functions which must be satisfied for any energy information model. However, in our opinion, the unavailability of standards has not been the primary cause of poor documentation. Rather, poor documentation results from modeler perceptions and technical project officer expectations which do not properly account for the legitimate documentation needs of various model clients. Clients include modelers, model analysts and users, model sponsor management, operators and users both at the sponsor site and potentially at other sites, decision-makers, and affected constituencies. Meeting the legitimate documentation requirements of these various model clients requires a planning process which considers documentation needs in the context of environment for the model development and use. Factors to consider would include:

- importance and scope of policy issues being modeled,

- diversity of potentially affected policy constituencies,

- potential contribution to state of the art,

- role of model sponsor in policy process,

- potential model users and clients (e.g., other modelers, analysts, operators, decision makers),

- logistics of model use (e.g., hardware and software requirements, proprietary software and/or data, need for portability),

- probable applications (e.g., specific to one issue or many, perceived importance in the policy process).

All these factors must be taken into account when translating the EIA. Interim Documentation Standards into a documentation $\mathrm{pl}$ an which reflects buth the legitimate documentation needs of model clients and the codification of EIA resource requirements analys is and budgeting. Accordingly,

Recommendation 4: Each model development and model application project should include the preparation of a documentation $\mathrm{pl}$ an as a joint responsibility of the technical project and evaluation officers. The documentation $\mathrm{plan}$ should include an analysis of the 
expected documentation needs reflecting the factors mentioned above, a description of the document types, an analysis of public access requirements and an access implementation plan. In general the depth of analysis and description should be sufficient to make clear the requirements, and the criteria for evaluating documentation performance.

A significant problem for the EIA in meeting certain types of documentation requirements may be the lack of periodic publications. The primary EIA publication forms are technical reports and Congressionally mandated reports, al though information bulletins are also published on occasion. The only periodic publication not mandated by congress is the Monthly Energy Indicators (MEI). The scope of the MEI has been limited to data publication and interpretation. In that respect, it is similar in concept to parts of the Survey of Current Business and the Monthly Labor Review. It is dissimilar, however, from these publications in that no articles on analytical efforts or major applications are included. Such survey articles are an important means of disseminating information on analytical efforts, major studies, and relevant information to the broad community of those interested in energy data, research, and studies. Accordingly,

Recommendation 5: The Monthly Energy Indicators should be expanded to include articles prepared primarily by EIA staff, surveying important data development, modeling, and model application efforts. As appropriate, articles discussing the highlights of mandated reports, such as the Administrator's Annual Report to Congress should be included.

Much of the EIA activity is devoted to scientific research on the organization, behavior, and performance of the energy system and on developing models intended to support EIA studies. These research activities are intended to increase scientific knowledge and understanding of the energy system, and for use in policy evaluation and analysis models. To be useful, such research results must be accessible to the relevant research communities, and sufficiently well-described to permit replication, counter-analysis, and general peer review.

Recommendation 6: More effort and encouragement should be given to submitting the results of EIA-sponsored research for publication in the relevant scientific literature. Such effort and encouragement should be reflected in the documentation planning process for important research and model development projects. 
C. Model Access and Archiving

The principal means of providing access to EIA-sponsored models and major applications is through the National Energy Software Center at Argonne National Laboratory. The present policy calls for the certification and transfer of all models and associated data used in the preparation of the Administrator's Annual Report to Congress. Interviews with representatives from both OAO\&A and NESC indicate that the transfer has not proceeded as rapidly or smoothly as anticipated for several reasons. E.IA has generally failed in satisfying the transfer requirements imposed by NESC, has not devoted sufficient personnel resources to satisfy NESC documentation and certification requirements in a timely fashion, and has informally expressed concerns about the costs of transfer, especially computational costs for replicating test problems. Our informal survey suggests that the effort may not be in major long-term difficulty, but does require either reemphasis of its importance by EIA management, or a reconsideration of the role of the NESC in satisfying the EIA archiving and access requirement.

The possibility of reconsidering the role of the NESC should be evaluated by EIA. The experience in transferring the PIES (MEFS) model to Texas A\&M University indicated that for a system of this complexity, access for a competent user involves more than just delivery of computer tapes and documentation. In a workshop summarizing what had been learned from the Texas experience, the Assistant Administrator for Applied Analysis, Roger Glassey, is quoted as saying.

"First, the exercise made it clear that existing EIA model documentation was inadequate. Second, the exercise helped clarify procedures for documentation and for understanding the meaning of model access. Third, the exercise made it abundantly clear that the mailing of computer tapes and written documents is not adequate to accomplish the $k$ ind of transfer needed for competent but new users to be able to set up and operate large scale models such as MEFS" (Holloway [1979]).

Based on the experience of this project (Texas National Energy Modeling Project), the Texas Energy and Natural Resources Advisory Council (TENRAC) has invited EIA to consider the annual transfer to Texas A\&M of the models and associated data used in preparing the 
Administrator's Report to Congress, with the understanding that the Texas group would actively participate with EIA in completing the nonmechanical portions of the transfer and would support other competent users in obtaining and/or using the system. The seriousness of the TENRAC interest is emphasized by the fact that the Texas legislature has required the TENRAC to conduct an evaluation and counter-analysis of the Administrator's Annual Report to Congress. The TENRAC intention is to employ the EIA modeling system, as appropriate, as the framework for conducting the evaluation and counter-analysis. Clearly, EIA can accomplish many of its objectives of providing access both to its models and to model-based applications by cooperating with the TENRAC. Accordingly,

Recommendation 7: EIA should formally reconsider its program of archiving models and model-based applications at the Argonne National Energy Software System, either reemphasizing the importance of the program and devoting sufficient resources to ensure its success, or abolishing the program.

Recommendation 8: EIA should accept the Texas Energy and Natural Resources Advisory Council offer to transfer to Texas A\&M University the modeling system and associated data used in support of the Annual Report to Congress (ARC), for use in supporting the TENRAC evaluation of the ARC, and for access by other competent users.

For many EIA models the level of detail and resolution makes the model difficult to understand and to access even for the competent user. Many users are interested in investigating the sensitivity of model-based results to changes in key input data and parameters where they have some knowledge of the likely distribution of these data. Conducting such studies with the full models is likely to be very difficult for these users without the direct cooperation of EIA, which under current access policy would be an exception. Yet, the capability to perform such studies would significantly contribute both to the utility of the model, and to the competent user's understanding of $i$ ts performance, and therefore to its credibility (when warranted). In many instances, such sensitivity calculations can be performed using approximations to the detailed model. Various methods are possible, but all essentially involve calibrating a "reduced form" model which relates key model output variables usually generated by repeated solution of the full model with key inputs and parameters varied according to a sample design, and other 
inputs held constant at their "reference case" values. For certain model types, a reduced form may be obtained analytically from the underlying structural parameters. For nonlinear models, the reduced form model provides an approximation to the structural model's response surface for some region of input data and parameter values. A desirable characteristic of such approximating models is that they are easily implemented and manipulated in interactive computer mode. This means that the designer can control the range of values which a user can submit, and generally include appropriate cautionary information to facilitate interpretation. We believe EIA could benefit greatly from the development of such reduced form for important models, both in its own work, and in providing increased access to important models. Accordingly,

Recommendation 9: EIA should devote research and attention to developing "reduced-form models" of important EIA energy information systems, especially the systems employed in support of the Annual Report to Congress.

The EIA and its primary contractors have participated in almost all of the EPRI/Stanford Energy Modeling Forum studies. Presumably, the EIA has found such participation to be valuable, both in providing increased understanding of the research and modeling activities of other scientists, and in increasing the exposure and understanding of its own models and modeling research. A logical next step for EIA would be to provide increased support for Forum-like activities, perhaps by sponsoring Forum studies focused on particular issues of interest and importance to EIA. A related idea would be to utilize the Forum organization approach to policy studies for an application of EIA models involving non-EIA modelers, model users, and policy analysts. Such an effort would greatly facilitate the access of non-EIA users and analysts to EIA models and model-based results and, if warranted, would certainly increase confidence in these models and in EIA model application processes.

Recommendation 10: The EIA should seriously consider augmenting its current public access policy by employing the EPRI/Stanford Energy Modeling Forum approach in organizing and conducting analysis of selected energy information issues. 


\section{Energy Model Analysis and Evaluation}

The EIA (and its predecessor agencies) have supported, or participated in, several evaluations of important EIA models. The version of PIES used in the National Energy Outlook-76 was evaluated, with EIA support, by modelers (primarily academic) organized and directed by Resources for the Future. As noted, EIA has cooperated with the Texas Energy and Natural Resources Advisory Council in transferring the versions of the model associated with the National Energy Plan and ARC-77 to Texas A\&M University, and cooperated in providing information necessary for the independent evaluation of these models. More recently the EIA/OAO\&A has been sponsoring model evaluation projects at the National Bureau of Standards (Oil and Gas Supply models), LOS Ail amos (Electricity Supply and National Coal Models), University of California at Berkel ey (Regional Demand Model), and the MIT Energy Model Analysis Program (ICF Coal and Electric Utilities Model). Finally, EIA organized and conducted an evaluation of the Regional Economic and Demographic Model (READ), employing a panel of independent consultants.

With the exception of the READ Model, all the EIA model evaluation projects have focused upon relatively mature modeling efforts. By their nature policy models are continually evolving, being updated, extended and changed to suit the needs of the issues at hand. However, the research results and concepts upon which the policy model is based tend to be more stable. This suggests that evaluative efforts should concentrate as much upon the component research models and concepts, as upon their integration into a system for analysis of particular issues.

The need for timely evaluation, as well as the nature of the model development process itself, suggests that the evaluation process should, to the extent possible, parallel the model development process. The stages of model development relevant for planning independent evaluation include: motivation and rationale, conceptualization, formulation, implementation, interpretation, and modeler evaluation. Approaches to evaluation vary by depth of analysis and materials used and include literature review (conceptual and contextual analysis), overview analysis (review of documentation including computer codes), independent audit (evaluator-designed/modeler-implemented computational experiments), and in-depth evaluation (independent control of model). The actual 
organization of evaluation will depend upon the stage of development and the appropriate approach, and would include peer review from within EIA, independent consultants, expert panels (e.g., READ evaluation), and independent model evaluation groups.

Thus, there are many factors to consider in planning the stages, approaches, and organization of the evaluation process. The responsibility for planning the evaluation, coordinating evaluation with development, and ensuring that the interests of EIA are well represented in the plan, and then implementing the plan should be one of the principal tasks of the technical evaluation officer (Recommendation 2). Accordingly,

Recommendation 11: Model evaluation should parallel model development. The integrative analysis concerning objectives, approach, and organization of evaluation should be a primary responsibility of the technical evaluation officer.

Section 31 of the Energy Conservation and Production Act of 1976 provided important amendments to the Federal Energy Administration Act of 1974 regarding the PIES model and access to it. In particular, subsection (3) required that the Administrator of the Federal Energy Administration "permit the use of such model on the computer system maintained by the Federal Energy Administration by any member of the public upon such reasonable terms and conditions as the Administrator shall, by rule, prescribe. Such rules shall provide that any member of the public who uses such model may be charged a fair and reasonable fee, as determined by the Administrator; for using such model." Subsequent legislation did not change the substance of this requirement. To our knowledge, no member of the public has yet requested such access; however, also to our knowledge, EIA has not established any criteria for "reasonable terms and conditions" or for the fee. In order to be prepared for such a legal request, we suggest the following:

Recommendation 12: EIA should es tablish a simple set of guidel ines or criteria to be met by any member of the public who wishes access to PIES (MEFS) in accordance with Section $31(3)$ of the ECPA of 1976. The fee to charge for such access and the possible provision of personnel to assist such users should be considered when drawing up the guidelines. 
2. Energy Information System Documentation, Public Access, and Evatuation: Organization, PoTicies, and PTans

Since the OPEC oil embargo of 1973-74, the federal government organization of energy data development and analysis, as well as energy policy analysis, has evolved from a situation in which these activities were fragmented among several agencies to one in which these responsibilities have been centralized in a Department of Energy, with the former functions located in EIA, and the latter in the Office of Policy Evaluation. In this section we describe the current organization, policy, and plans of the EIA as they relate to model documentation, public access, and evaluation. Appendixes $A$ and $B$ provide more detailed background information on the Congressional concerns and on related policies of other government agencies, respectively.

\subsection{Background}

In the immediate post-embargo period, organization of energy data development and analysis, and energy policy analysis and formulation were priority activities for both the Administration and the Congress. In rapid succession the Federal Energy Office (FEO), soon replaced by the Federal Energy Administration (FEA), and the Energy Research and Development Administration (ERDA) were organized. Compared with what was to come, relatively little attention was devoted to distinguishing energy data development and analysis from policy analysis and formulation. However, following the publication of the first Project Independence Report (Federal Energy Administration [1974]), the Congress, both in hearings and legislation, expressed concern about the credibility of available energy data and of studies and analyses using those data, and in particular the Project Independence Evaluation System (PIES). They feared that analysts within the government were too closely related to the energy industry--in particular the petroleum industry--to prepare truly independent and objective reports; that the Executive Branch was exerting influence on the data development analysis efforts to support particular Administration policy positions; and that the assumptions and interpretations of particular analyses were not well grounded in scientific knowledge, were not well documented, and could probably not be replicated. 
These concerns led to a number of related Congressional actions. First, the Energy. Information Administration (EIA) (and predecessor agencies), was organized so as to insulate the energy data and analysis functions from the policy formation and analysis functions of the Department of Energy (and predecessor agencies) (U.S. Congress, P.L. 94-385 [August 14, 1976]). This was accomplished in part by organizing EIA as an Administration with direct reporting responsibilities to Congress.* Perhaps most significant of these reporting requirements is the Administration's Annual Report to Congress, presenting short-, medium-, and long-term analyses of energy supply, demand, and consumption independent of the policy analysis function of the DOE (Energy Information Adminis tration [1979]).

Second, Congressional and public access to the PIES and related models on "reasonable" terms was mandated (U.S. Congress, P.L. 94-385 [August 14, 1976]). In addition the GAO was asked to provide an assessment of the PIES (General Accounting Office [1975]), and the House Subcommittee on Energy and Power commissioned its own PIES evaluation (Optimal Analysis Company [1976]).

Third, an independent Professional Audit Review Team (PART) was established to conduct an annual audit of EIA activities, and to report its findings directly to Congress (U.S. Congress, P.L. 94-385 [August 14, 1976]). * The first PART report, published in December 1977, apparently confirms many of the Congressional concerns. Thus,

"...the credibility of OEIA's [now Energy Information Administration] models has not been established because documentation, verification, and validation have been neglected. Furthermore, publications describing the current models are scarce, and procedures for public access to them are almost nonexistent. As a result, it is practically impossible for interested parties outside FEA [now part of the Department of Energy] to know whether OEIA's current models have been constructed properly and used correctly and thus whether OEIA's analytical products and forecasts can be used with confidence " (Professional Audit Review Team [1977]).

*Among others, Hogan (1978) has argued that this concern with ensuring the integrity of the energy data and analysis function has tended to greatly reduce the effectiveness of EIA, and its relevance in the policy research process.

**The PART is composed of a representative from each of six agencies including the General Accounting Office (Chairman), the Securities and Exchange Commission, the Bureau of Labor Statistics, the Federal Trade Commission, the Bureau of Census, and the Council of Economic Advisors. 
The report also questions EIA's procedures in distinguishing model development activities from model applications, and makes a series of recommendations including improved documentation, better control of model changes, validation of model structure, verification of model implementation, sensitivity testing to increase understanding of model response to changes in data inputs, and increased public participation of researchers outside FEA in professional review.

These Congressional actions are unprecedented and suggest the importance that the Congress attaches to ensuring the integrity of the energy data acquisition and analysis functions. The issues raised adequacy of documentation, public access to government based models, and credibility of analysis all indicate that the Congress is deepiy concerned about the role of policy models in energy policy research and decision making.*

The Energy Information Administration (and its predecessor agencies) have undertaken a variety of actions to address these concerns, and to develop and implement "good scientific practice" as part of their model development and application programs. Partially in response to the PART recommendations, EIA has established the Office of Analysis Oversight and Access in the Office of Analysis, and the Division of Model Validation in the Office of Energy Information Validation. The EIA/OAO\&A, to date the more active of the two, has undertaken assessments of important EIA inodels, as well as formulating and implementing procedures to facilitate documentation and public access. These actions include promulgation of interim documentation standards (Energy Information Administration [1978b]), and developing plans to transfer the PIES system and associated data, as well as other important EIA energy models, to the Argonne National Laboratory Software Center as a means of facilitating public access. More immediately, the EIA has been responsive to the requests of the Texas Energy and Natural Resources Advisory Council (TENRAC) for assistance in transferring PIES to Texas A\&M University in support of an independent, in-depth assessment by TENRAC.

*No other agency in the federal statistical establishment has been subjected to such intense scrutiny, nor have their activities been so circumscribed as have EIA's. 
In addition to the various organizational initiatives described above, EIA has undertaken and/or supported a number of assessments of important agency models. The first major assessment supported by EIA (at the time FEA) was the Resources for the Future assessment of the version of PIES used in the first National Energy Outlook (Landsberg [1977]). More recently EIA has undertaken assessments of the Regional Energy and Demographics Model (READ) (Freedman [1980]), the National Coal Model (NCM), the Oil and Gas Submodels of the PIES, and the Electric Utility Submodel of PIES. Finally EIA has supported a study by Logistics Management Institute (LMI) to analyze the al ternative means by which EIA can respond effectively to the public access requirements mandated by Congress (Shaw et al. [1978]), and the present study.

We now turn to a description of the EIA organization, policies, and plans as they relate to energy information system documentation, public access, and evaluation. 
2.2 Organizational Structure of the EIA

The Energy Information Administration is organized into eight major offices:

\author{
Office of Energy Data \\ Office of Applied Analysis \\ Office of Energy Information Validation \\ Office of Program Development \\ Office of Energy Information Services \\ Office of Management Services \\ Office of Planining and Evaluation \\ Office of Project Accountability and Controi
}

Two of these offices, Applied Analysis (AA) and Energy Information Validation (OEIV), are of particular interest due to their involvement in the generation, evaluation, and maintenance of energy models.

\title{
2.2.1. Applied Analysis
}

Each of the Offices of Applied Analysis and Energy Information Validation is divided into smaller sections, organized by subject matter. Applied Analysis has five such offices: Energy Source Analysis, Energy Use Analysis, Integrative Analysis, Energy Industry Analysis, and Analysis Oversight and Access. The latter office (OAO\&A) is most directly involved with model documentation and assessment activities.

The 1978 Annual Report to Congress has provided the following description of the activities of OAO\&A:

"The Office of Oversight Analysis and Access provides standards and procedures governing access, documentation, and technical review of applied analysis models and products. Primary attention is directed to evaluation of the datá and methodology of analysis, and to the assessinent and validation of models" (Energy Information Administration [1979]).

The office is composed of 16 full-time staff members as follows: one director, one administrative officer, ten analysts, and four secretaries. Responsibilities of OAO\&A include the following:

1. Administrative duties, notably the clearance of products and publications

2. Program areas, including

- Model documentation (developing documentation standards or guidelines for EIA-sponsored model efforts) 
- Model verification (determining that the models are operating as the model developer intended)

- Model validation (determining the quality of the model's structure and results)

- Model archiving and portability (enabling the transfer of EIA models to other locations)

- Model simplification (enhancing comprehensibility of complex models through simplification techniques)

3. Technical support, providing technical expertise to project research.

\subsubsection{Information Validation}

The Office of Energy Information Validation (OEIV) is also involved in evaluation of analytical energy models. One of the main purposes of the: office is the "validation of models and analyses", and the office is broken down into three smaller departments as follows: the Office of Validation Resources, the Office of Validation Analysis, and the Office of Systems Validation. OEIV has a total staff allocation of approximately fifty persons, with ten in Validation Resources, twenty-five in Validation Analysis, and fifteen in Systems Validation.

The Office of Validation Analysis is directly concerned with model evaluation. Thus,

"The Office of Validation Analysis analyzes and evaluates the requirements for, and the consistency of, energy informaton systems and plans for specific validation studies. This office also is responsible for validations of projections and models" (Energy Information Administration [1979]).

In fact, the Office of Validation Analys is is itself further divided into three subdivisions, one of which is entitled "Division of Energy Model Validation." According to the "Missions and Functions" statement issued by EIA and dated April 1978, the purposes of this division are to ". . determine the effects of modeling and forecasting techniques upon the meaning and accuracy of the data, and to evaluate the appropriateness of models and forecasts for satisfying Federal requirements for energy information." Specific tasks include:

'o Developing the necessary tools and procedures to validate projections of energy statistics and the models upon which they are based. 
- Analyzing and evaluating the limits of applicability for the models used to project energy supply, demand, distribution, consumption, and pricing statistics.

- Reviewing and validating the requirements for data collection to support EIA's modeling and forecasting activities, and based upon the sensitivity of the models and forecasts to variations in input parameters, assisting in the establishment of data collection accuracy specifications.

- Analyzing and evaluating the meaning and accuracy of model and forecast outputs.

- Reviewing standards proposed by the Office of Analysis Oversight and Access for: documentation of the models; disclosure of the accuracy and limitation of model output; validation of models; and validation of model inputs.

- Ensuring the actual independence and appropriateness of all "independent reviews" of models and projections performed by or for EIA. 
2.3 EIA Policies and Plans Relating to Energy System Documentation

2.3.1 Background

When policy modelers and model users meet it is a certainty that the topic of model documentation, or lack thereof, will be discussed, usually with considerable emotion. The gist of such discussions seems to center on differing perceptions by modelers and user/analysts as to what constitutes appropriate documentation. As one example: In 1976 at the EPRI-sponsored Workshop for Considering a Forum for the Analysis of Energy Options, the importance of appropriate documentation in establishing credibility of energy system models and model-based studies, al though not on the Workshop agenda, was discussed with increasingly sharply worded exchanges between modelers and user/analysts.' The Workshop report summarized the issues raised in the discussion as follows:

"The call for better documentation was repeated by nearly every speaker. The existence, timel iness, completeness, readability, dissemination, and purposes of most documentation were challenged or criticized by the workshop participants. The importance of a comprehensible documentation was emphasized to the degree of producing a proposal that the function of the Forum is to read and translate detailed model documentations. However, the sanctity of belief in good documentation was challenged by counter charges that current documentation is not read. There is no financial support for documentation preparation because, despite the rhetoric, users are not interested in having or reading documentation. When combined with the problems of disseminating proprietary information or defining good documentation, there is evidence of a major issue which deserves further discussion in the profession" (Stanford Institute for Energy Studies [1977], p. III-5).

The need for "further discussions" was emphasized further by the unprecedented congressional attention to the documentation of the FEA Project Independence Evaluation System (PIES) expressed in Section 113 of the Energy Conservation and Production Act of 1976 in which "full and complete" structural, parametric and operating documentation was required to be produced for the model. The EIA has responded to the letter and spirit of the Congressional concern in three ways: (i) by contracting for the documentation of the PIES (Logistics Management Institute [1979]); (ii) by developing a plan for developing and maintaining documentation for all existing EIA energy information models (Office of 
Analysis Oversight and Access [1979]); and (iii) by developing interim documentation standards to be applied in all new model development projects (Energy Information Administration [1978b]). The EIA Interim standards include five types of documents as follows:

1. Model Summary: A short, one to two page, nontechnical description of the model. These summaries describe the model's role and usefulness in DOE analyses, its general structure including inputs needed and answers produced, its relationship to other models, and finally the status of any ongoing enhancements or model development. These summaries would be used to provide general information about the modeling activities of EIÁ.

2. Methodology Description: This constitutes a detailed description of a model's rationale, precedent for the model in the literature, and comparison to other similar models or approaches. This level of documentation details the capabilities of the model as well as its assumptions and limitations. The basic purpose of this documentation is to explain why the model structure chosen was selected and to communicate how the model compares to, and was chosen over, al ternatives.

3. Model Description: A statement of the equations and other procedures which constitute the formal model structure, a description of the data. and other information utilized in developing the model structure, statistical characteristics of estimated portions of the model and any other information necessary to an understanding of what the model is and how results derived from the model are obtained.

4. Guide to Model Applications: A nontechnical description of how to use a model for analysis or forecasting, how to specify alternative input assumptions and data, and how to interpret model output. The purpose of this documentation category is to communicate the range of issues the model is designed to address and the limitations of the model. The intended audience are those who would use model results.

5. User's Guide: This constitutes a detailed description of a model's operating procedures including names and locations of input files and computer programs, naming conventions, and required job control statements. These documents are intended for the use of EIA staff who actually operate the model on the computer and should enable an informed staff member to make model runs and label his input files and output files, so that subsequent users will be able to properly identify the files. An annotated listing of the computer program should be an appendix to the operating documentation. This documentation category will require frequent revision to be kept current. 
The current interim standards are under review and evaluation by OAO\&A. In April, 1979 a workshop of EIA contractors working in the area of model assessment was held to discuss effective standards for policy model documentation.* As a result a revised and much more detailed set of documentation standards, based largely on the proposals of Gass (1979a), is being considered by OAO\&A (National Bureau of Standards [1979]).

\subsubsection{Guidel ines for Planning Policy Model Documentation**}

The document types and general contents included in the EIA interim standards and the more detailed classification by Gass (1979) provide a framework and checklist for documentation planning. The details of a plan for any particular policy model will depend upon a variety of factors dictating the particular document types required, their extent, format, and style, and their costs (both financial and skills), consistent with the legitimate needs of the model clients. The objective of the documentation planning process is to ensure the systematic evaluation of these factors, and to effectively communicate the results so that model clients (including the modeler and model sponsor) share common expectations about the outcome, and so that sufficient resources are devoted to satisfying documentation needs.

Table 2-1 summarizes the factors to be considered in the documentation planning process. We distinguish the model development from its application environment. Analysis of the model development environment will be most influential in determining the extent of technical documentation required. A policy model based upon new scientific results, concepts, or methods, will require more comprehensive documentation than a model based upon well-estabijshed scientific results. Likewise the more important and conflicted the policy issues under consideration, the greater the need for extensive technical documentation which motivates and describes the modeling approach, the scientific results employed, and the associated data used to implement the model. While the fundamental criterion for technical documentation

*Organizations participating in the workshop included Argonne National Laboratory Energy Software Center, Idaho National Energy Laboratory, Logistics Management Institute, Los Alamos National Laboratory, MIT Energy Laboratory, and National Bureau of Standards.

$\star \star$ Reproduced from Goldman et al. (1979). 
Table 2-1

FACTORS FOR CONSIDERATION IN THE PREPARATION OF AN ANALYSIS OF DOCUMENTATION REQUIREMENTS

Environment for Model Development

- Importance and scope of policy issues to be modeled

- Diversity of potentially affected policy constituencies

- Potentiar contribution to state of the art

- Role of model sponsor in the policy process

Environment for Model Use

- Potential users and their needs

- Scientific peers, other policy modelers

- Policy analysts/users

- Operators

- Other groups concerned about the policy issue(s) under analys is

- Sponsoring agency

- model development sponsor

- application client

- Decision makers

- Potential Logistics of Model Use

- Hardware and software requirements

- Proprietary software or data considerations

- Need for portability

- modeler only

- single nonmodeler user at one site

- many nonmodeler users at many sites

- Probable end uses of model

- Specific to one application; specific problem-solving

- Foundation for broad policy decisions

- Forecasting many interrelated results 
is to ensure the understanding of peers, and possible replication of model implementation and model-based results, importance of issues and/or novel ty of scientific basis may dictate efforts beyond this minimum level in order to establish model credibility.

The application environment for a policy model also influences the documentation plan. Important factors to consider include the needs of the different model clients, the potential uses of the model, and the logistics of model use. Distinguishing the legitimate documentation requirements of the different clients for a policy model and for model-based analysis is perhaps the single most important factor in the documentation planning process. Clearly a nontechnically oriented decision maker will have a different set of needs than a policy analyst, a computer operator, or a scientific peer from the modeling community.

Potential model clients often overlooked in discussions of model documentation requirements are groups who have a vested interest in the policy issue under analysis. Technical docunientation, users' guides, and well-documented studies will partially satisfy the needs of such groups depending upon their analytic abilities. Planning for public access to the model may also help in meeting their concerns; the EIA project to transfer important models to the Argonne Software Center is a good example. But many groups will not have the analytical ability and/or resources to take advantage of such documentation or public access. When the importance of the users and the role of the model sponsor warrant it, more must be done to satisfy such groups that the models and model-based analyses are not "black boxes of predetermined results." Model sponsor support of peer review and evaluation of policy models and model-based studies with presentation aimed at both technical and nontechnical audiences is one way to deal with the legitimate concerns of this group.

A second major set of model characteristics affecting the need for documentation is that of the logistical requirements of the model design plan for use. As Table 2-1 indicates, such factors include data, hardware and software requirements, as well as consideration of the need for transferring the model. A model which was intended to be run by the developer at only one site might need different forms of documentation than one which was intended to be generally portable to a variety of sites. 
Finally, consideration must be given in documentation planning to the kind of model results wich will be produced. Has the model been designed to problem-solve in only one application with relatively simple and straightforward results, or will it produce a highly complex set of results that are interrelated in nature, complicated to analyze and apply, and perhaps controversial in terms of policy implications clearly, the document types, and their style, format, and content will differ between these two extreme applications.

Systematic planning for documentation requirements will go far to redress the problems of documentation discussed earlier. The minimum acceptable level of documentation, that which will permit full analytical review of the model, will furfill the most basic needs to justify scientific acceptability. Further documentation, as determined through the analysis, will fulfill the needs of analyst/users, operators and other model clients. Advance planning will contribute to understanding and common expectations among modelers, model sponsors, and other model clients. In short, a documentation planning process will lead to a more orderly, thorough and competent production of model documentation, and should significantly increase credibility and usability of the model. 
2.4 EIA Policies and Plans Relating to Public Access

The Energy Information Administration (EIA) has considered the issues concerning public access to EIA models and associated data, and has established criteria and procedures for their regulation. Through a series of in-house memoranda, private communications, and communications to the Professional Audit Review Team, EIA has made clear its intentions to "eventually provide decisive assistance to those who wish to acquire [EIA] models, duplicate the results of using the models ... or otherwise use the model to understand the nature of its results" (Lady [1979]). EIA defines this access to models as being satisfied in four ways:

- publication of all model input data and results used in DOE-published analyses;

- availability of customized runs (on a prioritized basis, with Congressional and Executive Branch requests having highest status, and other governmental requests being fulfilled only as time and personnel allow. Non-government requests are not fulfilled, reportedly due to lack of resources);

- capability of model portability (defined as the ability to make an EIA model operational at another site without the assistance of EIA personnel);

- availability of complete model documentation (0'Neill [1978]). However, fulfilling all of these criteria for full access to EIA models has been described as a "remote possibility" by an EIA official. Therefore the agency's current plans are to meet what they deem to be minimum acceptable requirements for model access, and aim at achieving portability rather than full access. These minimum standards would include the supplying of an operations guide, a set of test data with which to measure replication of results, model documentation, and users' guides (O'Neill [1978]). It should be noted that these portability guidelines are applied only to those systems which will accept EIA software without modification, such as translation to other computer languages. Therefore these standards are clearly minimal at best, do not cover all possibilities for use, and address only operational access, not conceptual assistance.

As a means of responding to Congressional mandates (see Appendix A) and establishing access to government energy models, the Energy Information Administration has transferred three of its models-- 
the Project Independence Evaluation System (PIES), the Regional Demand Mode1 (NESC), and the $0 i 1$ and Gas Model--to the National Energy Software Center (NESC), a part of the Argonne National Laboratory.* The NESC was originalily organized by the Atomic Energy Commission to distribute programs written in areas of nuclear physics, reactor design, and engineering. In 1972 the Center was expanded to accept codes from other sources, and it presently receives funding from both the Nuclear Regulatory Commission and the Department of Energy.

NESC operates through registered installations. Organizations wualify as either waiver-list or subscription-fee installations. Installations sponsored by agencies funding the NESC program, those designated by either government agencies or computer software information centers with whom exchange arrangements. exist, or others recognized as contributors to the NESC program, are waiver-list establishments and receive NESC services without charge. Establishments not meeting the above requirements are subscription-fee installations and pay the cost of services requested. Subscription-fee installations pay a first-year fee of $\$ 285$ to cover the cost of establishing and maintaining installation records and supplying publications and other information services; the yearly renewal fee is $\$ 135$. Computer programs are generally supplied to requestors in the form of magnetic tape and documentation. At present, approximately 610 organizations are registered, and the Center fills about 1,000 requests per year for program packages. NESC currently is maintaining nearly 700 programs, but work is under way to el iminate those that are now obsolete.

Before NESC distributes a program, the program's sample is run by Center personnel, and the results are compared with those provided by the model developer. NESC provides to program submitters a description of "Recommended Program Package Contents" which a model submitted to them for archiving should meet. Items on this list include source decks, run decks, sample problems, data libraries, control information, auxiliary information, and printed documentation. While every item is not

\footnotetext{
*The following description of NESC is based on communications with Marianne Legan and Margaret Butler of the Argonne Institute.
} 
required, material submitted to the Center must be sufficient to enable successful operation of the program. The emphasis is clearly on operational data and documentation; conceptual and methodological explanation of the model are not critical to the archiving process.

Assistance to users is provided by NESC only in a technical, or operational, sense. Because program reviewers at the Center have gone through the process of putting the models up on their own system, they are often "able to "troubleshoot" by telephone, and solve new users" operating problems. Conceptual assistance is not supplied, however. If a user needs further comprehension of methodological issues, or is concerned with changing the model to suit a particular application, NESC refers the user to the model developer. Administrators at NESC do not feel that the EIA models will be treated differently from the NRC models in this regard.

NESC has encountered a great deal of difficulty in getting PIES operational for several reasons. Some of the original tapes were written at a different density than was indicated in the documentation.. Some of the programs produced underflow, overflow, and divide check errors or had uninitialized variables. Documentation was inadequate.

Proprietary software also presented a serious problem. The PIES model required use of the MAGEN and MPS-III packages. NESC purchased MPS-III. MAGEN, however, was not available for purchase and was leased from the developer for a six-month period ending February 1980 . Users who request the PIES model from NESC will also have to purchase MPS-III and rent MAGEN separately. The Regional Demand Model uses the TSP and MAPS packages. NESC purchased TPS, but was unable to find where MAPS originated. Users of this model will have to buy TSP. The files created by MAPS are included with the model.

By October 1979, the $0 i 1$ and Gas Model, the Regional Demand Model, and PIES were running; however, NESC output does not entirely match the output produced at EIA. Reasons for these discrepancies are being sought from EIA, but at this time they have not been resolved.

The tasks which rema in before the EIA models will be considered ready for access are to find and reconcile all result discrepancies, produce a master tape from which copies will be made, and retest each 
model using the master tape. At this time, NESC has two requests for the EIA models. These are being held until the system is ready.

EIA has indicated to NESC that it intends to transfer the next version of PIES, MEFS, to the Argonne Center at some time in the future. It has also indicated that after October 1, 1979, EIA will transfer approximately 20 energy-related models to the center. However, EIA has contracted with outside consulting firms to test and refine those-models before sending them to Argonne. The purpose of this activity may be to speed up the process of archiving by reducing the number of operational problems which NESC must handle. The schedule for receiving these models is unresolved at this time, but NESC has estimated that 4-6 weeks of ful1-time effort would be required to get each model running if no unusual problems are encountered.

NESC has initiated publication of a "Bimonthly Bulletin" that will list available programs, including the EIA models. The "Bulletin" is sent to NESC subscribers, and NESC expects that more requests for EIA models will be generated after the publication is distributed.

\subsection{PART Comments on EIA Documentation and Public Access Policies}

The Professional Audit Review Team, established by the Energy Conservation and Production Act of 1976, has produced two annual reviews of the activities of the EIA. The first was published in December of 1977 after 10 months of operation of the Office of Energy Information and Analysis (OEIA), EIA's predecessor. The second PART report became available in May 1979. Both of these reports commented on the energy information agency's efforts towards establishing public access to energy models through documentation and direct access procedures. The first PART report (PART I) was extremely critical in this regard. In sum, PART I stated that the credibility of OEIA's models was not established, due to the lack of sufficient documentation, verification, and validation efforts. While PART I did not imply the models were necessarily incorrect, it concluded that it would be impossible to use the models or their results with confidence. Regarding public access specifically, PART I was also critical. The OEIA, it reported, was not organized in a way which permitted it to respond to public requests for access to models. Moreover, OEIA was criticized for maintaining an inadequate public review process for important reports (specifically the 1976 
National Energy Outlook) during which too few people were given too little time to understand and comment on the modeling products. Finally, OEIA was faulted for failing to make changes to models public along with the reasons for the alteration and the impact on results such changes would have. However, PART I did acknowledge that OEIA was responsive to requests for modeling runs from members of the Executive and Legislative branches of the government.

During the 17 months which el apsed before PART II was written, the DOE.was formed, and within it, the EIA. Specific plans were made to address the concerns outiined in PART I and echoed el sewhere, particularly to increase the credibility of government models and to become more responsive to access mandates. These included the documentation standards and the archiving of PIES at Argonne as mentioned above. PART II's review of EIA's efforts was much more flattering. The PART II report stated that the credibility of models had been enhanced in: 1978 due to the presence of an Applied Analysis program plan and interim documentation standards, which they believed would increase the usability of the models. Further, PART II stated that EIA now responds to specific requests for analytical data runs from DOE officials, Federal and State government representatives, Congressional Committee members, industry, academia, and the general public, and that a public listing of these requests is kept. Specific examples of the fulfilling of such requests were not supplied in PART II. 


\section{Energy Model Evaluation}

We now turn to a consideration of issues in effective organization and implementation of energy model evaluation within the EIA. We discuss approaches to evaluation, the key elements of model validation and verification, and the relation between stages of model development and of evaluation. In the final section we survey various energy model evaluation projects, including three sponsored by EIA.

The primary stimulus for the current interest in policy model evaluation, beyond scientific peer review, is the need to communicate evaluative information to nonscientific constituencies concerned with model validity and applicability to particular policy issues, and the need for organizations sponsoring model development to devel op their own standards and guidelines for good practice in both policy model development and application. A secondary, al though important motivation is the fact that many policy models are being developed by groups which may not have incentives for good scientific practice such as are encouraged by peer review, reference publication, and a strong scientific ethic.

Only recentiy has much attention been devoted to defining a) ternative approaches to assessment and to how assessments can be most efficiently organized. Perhaps most prominent in this regard have been the efforts of the EPRI/MIT Model Assessment Program who identify four increasingly detailed approaches to evaluation including,

Review of 7 iterature,

Overview assessment,

Independent audit, and

In-depth assessment.

The major distinction between the approaches concerns the materials used in evaluation. A summary of the relationships between these approaches. to assessment is given in Figure 1 (M.I.T. Energy Model Analysis Program [1979]).

A review of the literature for a model, or set of similar models, focuses upon model formulation, measurement and estimation issues relating to model structure, applicability for analysis of specific policy issues, and so on. Such a review may be both descriptive and evaluative. A classic example is the review by Taylor (discussed below) 
of electricity demand models which compares model structure with an "ideal" structure. In its various forms, literature review and analysis is the traditional means of model analysis. Issues of approach, logic, measurement and interpretation are formulated and analyzed. Issues of actual implementation are less susceptible to analysis with this approach.

An overview assessment uses the underlying technical model documentation, especially the computer code, for a more precise analysis of the model's structure and implementation. An overview evaluation can identify a policy model's critical points, but it will only occasionally be able to pass judgment on the adequacy of the model's treatment of them. The overview report is a useful intermediate stage in the assessment process, but assessment of the model's validity and: applicability generally requires the acquisition and analysis of experimental data.

An independent audit evaluates a model's behavior by analyzing data derived from experiments that are designed by the assessors but run by the modelers. An important el ement of the procedure is that the assessment group is "looking over the modeler's shoulder" while the experimental runs are being made. This is essential to the accurate interpretation of the results produced by the experiment. An audit report should use the experimental data together with the analytical material developed in previous stages of the evaluation process to determine the model's validity in as many key areas (critical points) as possible. Audit procedures have the advantages of being relativeiy quick and inexpensive. With complex models, however, there will generally be some critical points that cannot be fully evaluated through an audit.

An in-depth assessment develops experimental data through direct, hands-on operation of the model. Direct operation makes it feasible to carry out more complex tests, particulariy when the tests require modifications in model structure rather than simple changes in model parameters and/or data. Because of the significant costs of in-depth evaluation, it is probably most efficient to conduct exploratory analys is through an independent audit before embarking on more detailed evaluation. After an in-depth evaluation has been completed, audits might subsequently be used to update the evaluation as new versions of the model are developed. 
Four separate issues regarding the organization and conduct of policy model evaluation, and proposed procedural guidel ines for policy model evaluation.

Independent versus Comparive Assessments: There is a basic problem which must be confronted when evaluating a particular model as to the evaluation criteria. A model may represent the state of the art, and still be criticized for inadequacies in data and inability to deal effectively with basic research problems. Such an evaluation will provide no information establishing the strengths and limitations of the model as compared with other models potentially applicable to the same policy issues. The concern is that the potential user must be made aware of comparative strengths and weaknesses. The group concluded that this issue was a serious one, that comparative assessments should be undertaken in the future, and that the issue might become less controversial as independent evaluation became more widely practiced for developing models. In the next section several comparative model analyses oriented toward scientific audiences are noted.

Relations among Assessors, Modelers, and Sponsors: The group concluded that it is extremely important for the effectiveness of policy model evaluation that the relationships amongst assessors, modelers, and sponsors be spelled out, contractually if necessary, and that resources be provided for modeler participation in the assessment process. Modeler. participation is vital to minimize the existence of misunderstanding, to correct for gaps in the documentation, and to review assessment materials. In particular, review of the evaluation and the opportunity. for modelers to attach comments to evaluation reports was found to be a vital element both in ensuring modeler cooperation, and in ensuring that the potential user is made aware of modeler disagreements with the evaluation, and with modeler/analyst perspectives.

The Moving Target Problem: Important policy models being used in policy research tend always to be developing, incorporating new research results and data, and responding to new policy research applications. This fact complicates the identification of the standard, or reference, version of the model to be evaluated. It raises questions about how model analysts should deal with significant changes to the reference version of the model. Resolving these issues requires careful planning 
on the part of the evaluation group, as well as flexibility and good will on the part of modelers, model analysts, and sponsors.

Assessors as Modelers: Perhaps one of the most fundamental problems in model evaluation concerns the role of the model analysts as modelers. clearly, for evaluations to be effective and to carry weight in establishing model credibility, the assessors must be competent modelers. To the extent that assessors use the model assessment process as a means for identifying and then pursuing research issues, however, the assessment process is compromised. First, the modeler will lose confidence in the process and will not wish to cooperate. Secondly, the model analyst will be redirecting his activities from evaluation to research. At a minimum this represents an injustice to the assessmerit sponsor. Finally, the integrity of the evaluation process is seriously compromised when the assessor becomes a competitor to the modeler. Such competition is, of course, fundamental to advancement of scientific knowledge, but conflicts with objectives of communicating the results of evaluation to non-scientific audiences.

Procedural Guidelines for Model Evaluation: The EPRI/MIT group suggests the following guidelines for organizing and conducting policy model evaluation.

Assessor/Modeler Relations -- A formal agreement should be reached defining the relationships between modeler and assessor with regard to,

- resources to support modeler as well as model analysts,

- extent and nature of modeler/assessor interactions,

- confidentiality of intermediate results,

- opportunity for modeler response, and

- post-evaluation activities.

Potential Model Applications -- A wide-ranging list of potential applications of the model, incorporating suggestions from all interested parties, should be drawn up at an early stage to provide an explicit policy context for the evaluation.

Definition of a Standard Modei -- A standard version of a model must be agreed upon and "locked up" prior to the start of experimental analysis. It is desirable, however, to permit changes to be made during early stages of the evaluation, particularly if the changes are to correct errors uncovered in the overview evaluation. 
Assessors as Modelers -- Model analysts can and should suggest ways in which the model can be improved, but they should not themselves implement the improvements. To do so would compromise the integrity of the assessment process and would put the assessors in competition with the modelers.

\section{1 Elements of Policy Model Evaluation}

The elements of a policy model evaluation are much discussed and debated. The most often cited literature includes Gass (1977) and Greenberger, et al. (1976), Doth of which distinguish two fundamental aspects of model evaluation: validation and verification. Validation refers to the correspondence of the model to the underlying processes being modeled. Correspondence will include the structural features of the model, the inclusion of relevant variables--especially policy instruments and concepts of importance for the issues to be analyzed--and the predictive capability of the model. Structural evaluation is, of course; the essence of scientific analysis. Model structure is based upon the conceptual specification of the model, specification and application of the masurement process by which the model data are generated/obtained, specification and analysis of scientific hypotheses derived from theory underlying the model and to be tested via analysis of the model data, and selection of the final model best supported by the scientific laws, principles, maintained hypotheses, and tested hypotheses which were the resources and/or results of the research process. Validation of such a researcil model will include replication of measurements and hypothesis testing, as well as analysis and/or counter-analysis including the variables and concepts appropriate for logical coherence for analysis of the policy issues for which the model is intended.

It is for this latter purpose that content validity is usually singled out from structural validity, when considering policy models. Both policy evaluation and analysis require that models reflect the appropriate policy concepts and instruments.* A policy evaluation model. will be simpler than a policy analysis model in this regard in that only

*Greenberger, et al., distinguish policy evaluation and policy analys is as follows: "Policy evaluators organize a research effort around an existing program and ask how well it is achieving its intended objectives; policy analysts tend to organize their investigations around a set of policy objectives and they inquire whether there is any conceivable program or combination of programs that might achieve the desired ends more efficiently" (Greenberger et al. [1976], p. 30). 
the policy actualiy implemented and being evaluated must be included. Policy analysis models are more complicated in that the policy instruments and concepts suitable for the alternative policies of potential interest and importance to the various constituencies concerned with the issue(s) of interest must be included. Further the model must be explicit concerning the resolution of "facts" and/or value judgments which are in dispute among the various constituencies. Crissey (1975) has made evaluation of such model contention points a central feature of his approach to policy model analysis.

The third element of policy model validation is predictive capacity, determining if the scientific information and results included in the model are sufficient to discriminate amongst the policies being considered. If the range of scientific uncertainty spans the range of policy dispute, then the model's usefulness in policy research is very limited. Model-based studies reporting only point predictions with no information on prediction confidence limits or sensitivity analysis of predictions to changes in input data and/or structural coefficients, consistent with known or conjectured uncertainties in the underlying measurement processes and scientific results, may imply an unjustified precision of analysis. Analysis of predictive power is thus an important aspect of policy model analysis quite independent of the structural validity of the components of the model.

Closely related to the various dimensions of model validity is the validity of the data associated with the model. Data validation must include not only evaluation of the measurement process by which the data component of model structure is developed, but al so the processes by which the data required for model applications are obtained. While data and measurement process evaluation are closely related to model evaluation, particularly evaluation of model structural and predictive capability, it is probably useful to single out this aspect of validation since it typically receives so little attention in policy modeling and research.

Crissey (1975) has a similar perspective on the elements of policy model validation. He emphasizes that the credibility and utility of a policy model will depend upon its treatment of the factual, behavioral, evaluative, and structural issues in dispute. Disputed issues should be 
represented in the model in a manner facilitating analysis of al ternative resolutions. Such issues comprise the model's contention points. According to Crissey, a contention point is said to be critical if change in its resolution significantly affects the model conclusions and is a contingency point if changing the resolution of this contention point in combination with others results in a significant change in model result (Crissey [1975], pp. 83-88). This concept of model contention points provides a useful focus for structural, content, and predictive validation.

In contrast to validation, policy model verification refers to the evaluation of the actual model implementation. At issue is the correspondence of the implemented model--usually a computer program--to what the modeler intended. Verification is thus more mechanical and definitive than model and data validation. Gass (1977) has suggested that policy model verification is the responsibility of the modeler, and that evaluation should be limited to review of the verification process. In the next section, however, we will see that some of the more in-depth current policy model evaluation projects have included independent verification of implementation as an objective.

A final aspect of policy model evaluation concerns usability. This dimension of evaluation refers to both the sufficiency of documentation to support model understanding and applications, and the efficiency of the overall system. Technical documentation and materials sufficient to inform potential users of the model structure, content, and predictive characteristics, as well as to support interpretation of model-based results are essential for any policy model. The need for documentation to support independent application of the model, including user and system guides, test problems will depend upon the model application environment. Of course, even if the intent is for the modeler to conduct all applications, there still should be evidence that application procedures have been developed, and that a reasonable applications practice is in effect.

\subsection{Evaluation at Various Model Development Stages}

Ideally, model evaluation should be conducted in parallel with both model development and model application. Performing assessments during and following the application of a model has become a relatively common and productive activity. Examples would include the varying evaluations 
of the Project Independence Report, the RFF Evaluation of NEO-76, and the TENRAC evaluation of the version of PIES used in ARC-77. However, except for the model builder's self-evaluation exercises, formal evaluations of a model are generally not conducted at various stages of the model development process. There are several reasons for the unpopularity of this type of assessment, namely:

(1) analysts are generally not familiar with techniques for model assessments,

(2) there are logistical difficulties including

- a lack of understanding of model development stages,

- problems of identifying discrete stages in an intrinsically continuous and overlapping process,

- difficulties in coordinating the selection of a model version, feedback of assessment information, and resolution of points of content, and

(3) questions of cost-effectivness:

- it is difficult to know the worth of a model before development is completed,

- duplication of efforts between the builder's self-assessment and the independent developmental assessment, and

- value, objectivity, and credibility of an assessment so closely tied to model construction.

This section contains discussions of the last two issues, beginning with the definition of development stages, then discussing assessments that are appropriate at these various stages and how these developmental assessments might be organized and implemented at EIA.

\subsubsection{Model Development Stages}

Model development is probably most accurately characterized as a process that is an erratically progressing set of parallel and feedback modeling activities. It is a difficult and somewhat arbitrary task to define discrete stages of model development. It is, however, necessary to have discrete stages if assessment is to be conducted during model construction, because:

(1) there should be logical times for assessor/modeler review meetings, and 
(2) there must be quantized amounts of new model construction information in-hand at these review meetings.

The selection of model development stages is made more difficult by the lack of any available general methodologies for modeling. A previously published definition of stages is shown in the figure on the following page. This flowchart represents a quite detailed outline of model construction activities. Figure 3 represents a more workable framework of stages from the standpoint of model evaluation. Each of the development stages in Figure 2 represents a group of similar activities. The flowchart, in moving from top to bottom, moves from the ideal to the actual. Thus, each arrow of the flowchart represents an actualization of ideal el ements, being manifested as compromises, approximations, and other kinds of points of corruption in the model development process. After a set of decisions has been made about the actualization of several related ideas, there should be an assessment of the existence and extent of the corruptions. This topic is discussed in the following section; it should be noted that there are analogous points of corruption in the model application process, see Figure 4. This analogy is largely due to the redevelopment activities that can dominate the application process.

\subsubsection{Assessments at Development Stages}

Assessments of models can only be performed in the context of user expectations. These expectations ideally would be in the form of specific intended applications, but more realistically consist of generic or generally defined application areas. For example, the organizational structure of the model may be its most valuable product, as opposed to any informational value of the model. In such cases, there is an obvious advantage to evaluations during model development. But developmental evaluations can also have important degrees of effectiveness even for purely informational models.

The ideal form of model validation would involve taking the outputs from a model and comparing them with reality. Since most models are intended to be predictive of future events or other effects for which no measurement system exists, the ultimate validity comparison is generally not possible. In Figure 5 this ul timate mathod of assessment is shown as the dashed arrows on the far right of the diagram. Such a comparison is possible when a model is intended as a simplified characterization of a prototype or system that can be checked with any number of experiments. 
FIGURE 2

\section{BASIC STEPS IN THE MODELING PROCESS}

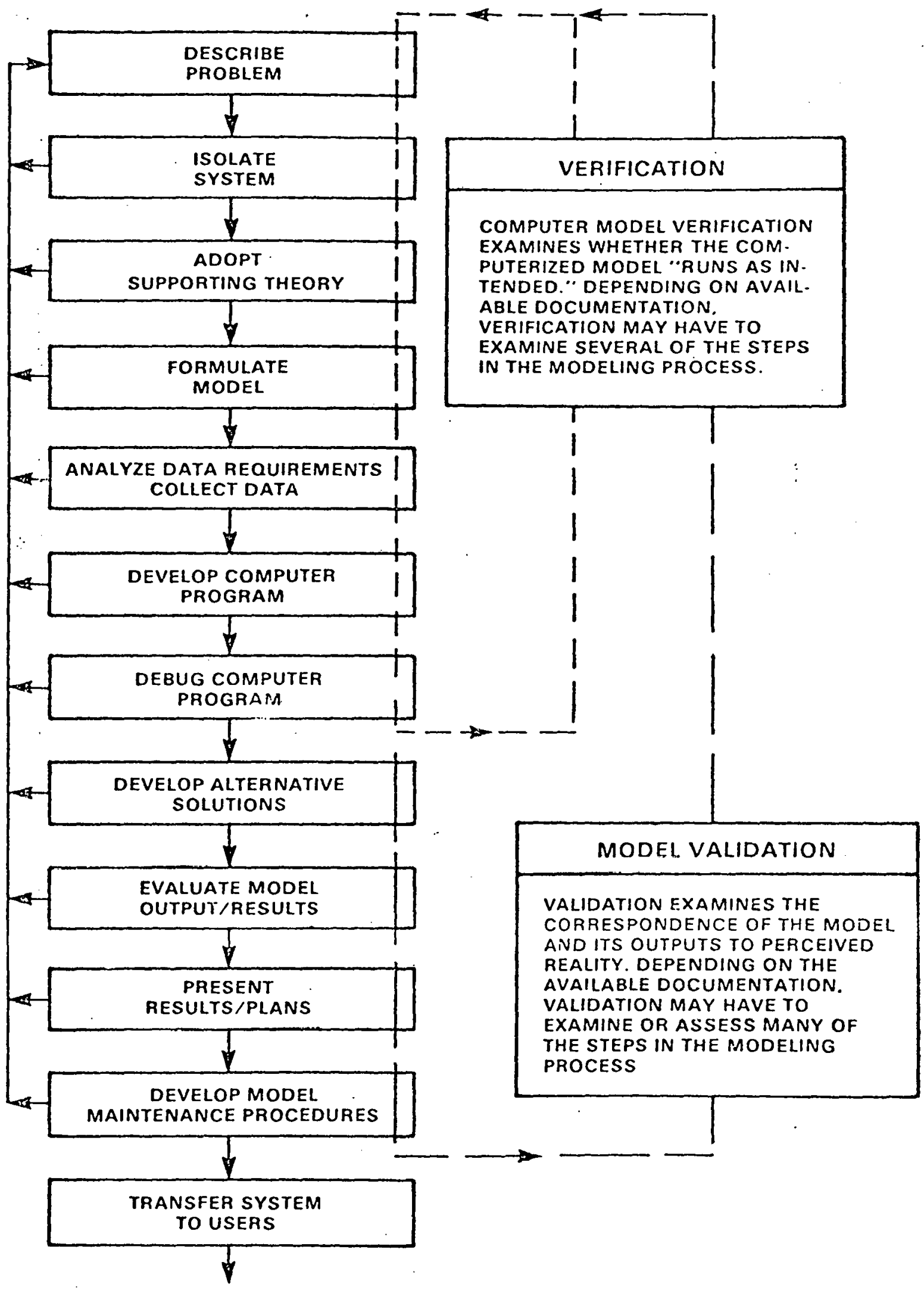

Source: General Accounting office (1979). 
STAGES OF DEVELOPMENT (activities and outcomes)

MOTIVATION

CONCEPTUALIZATION

RESEARCH PLAN

ERPIRICAL RESEARCH

IMPLEMENTATION

ASSESSMENT
DEVELOPMENT PROCESS

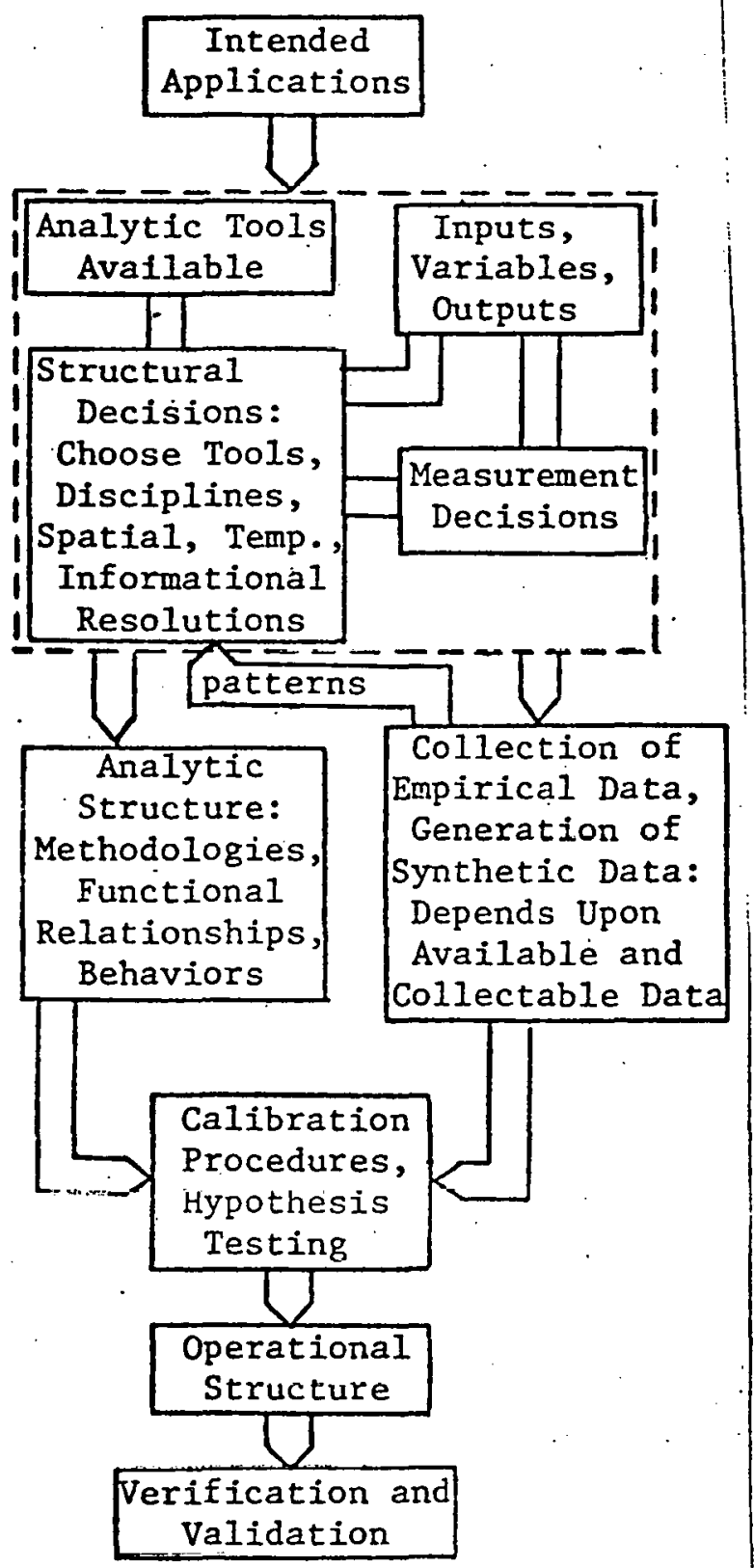

Figure 3 Stages of Model Development 
STAGES OF APPLICATION

UTILIZATION PROCESS

(activities and outcomes)

MOTIVATION

Applications

CONCEPTUALIZATION

FORMULATION

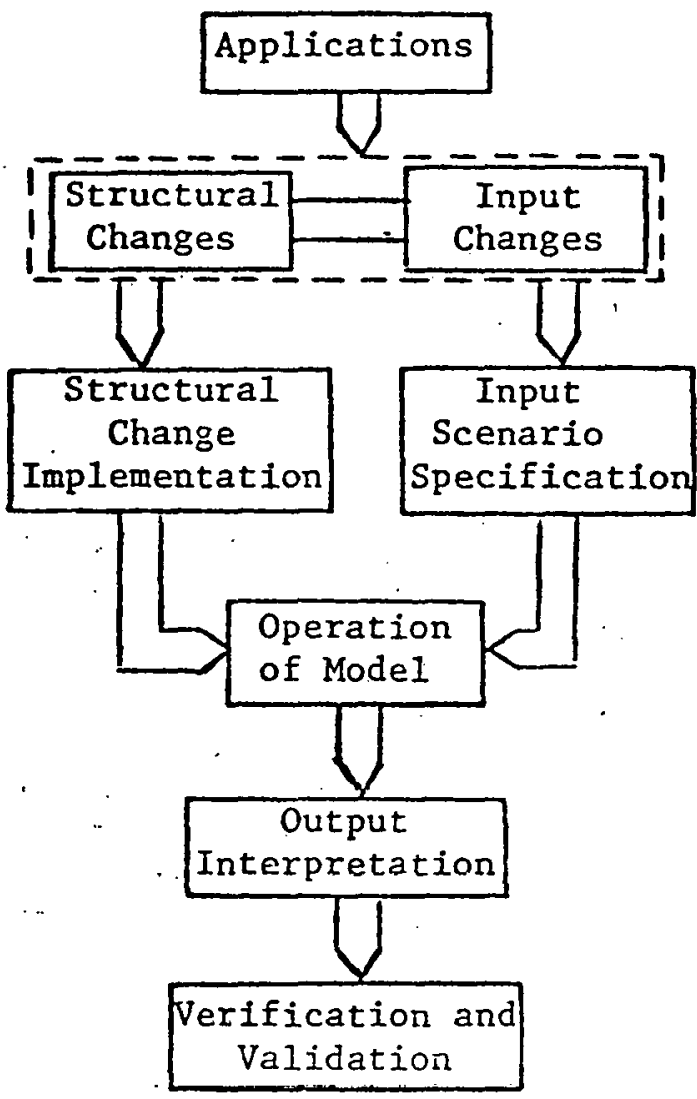

ASSESSMENT

Validation

Figure 4 Stages of Model Application 


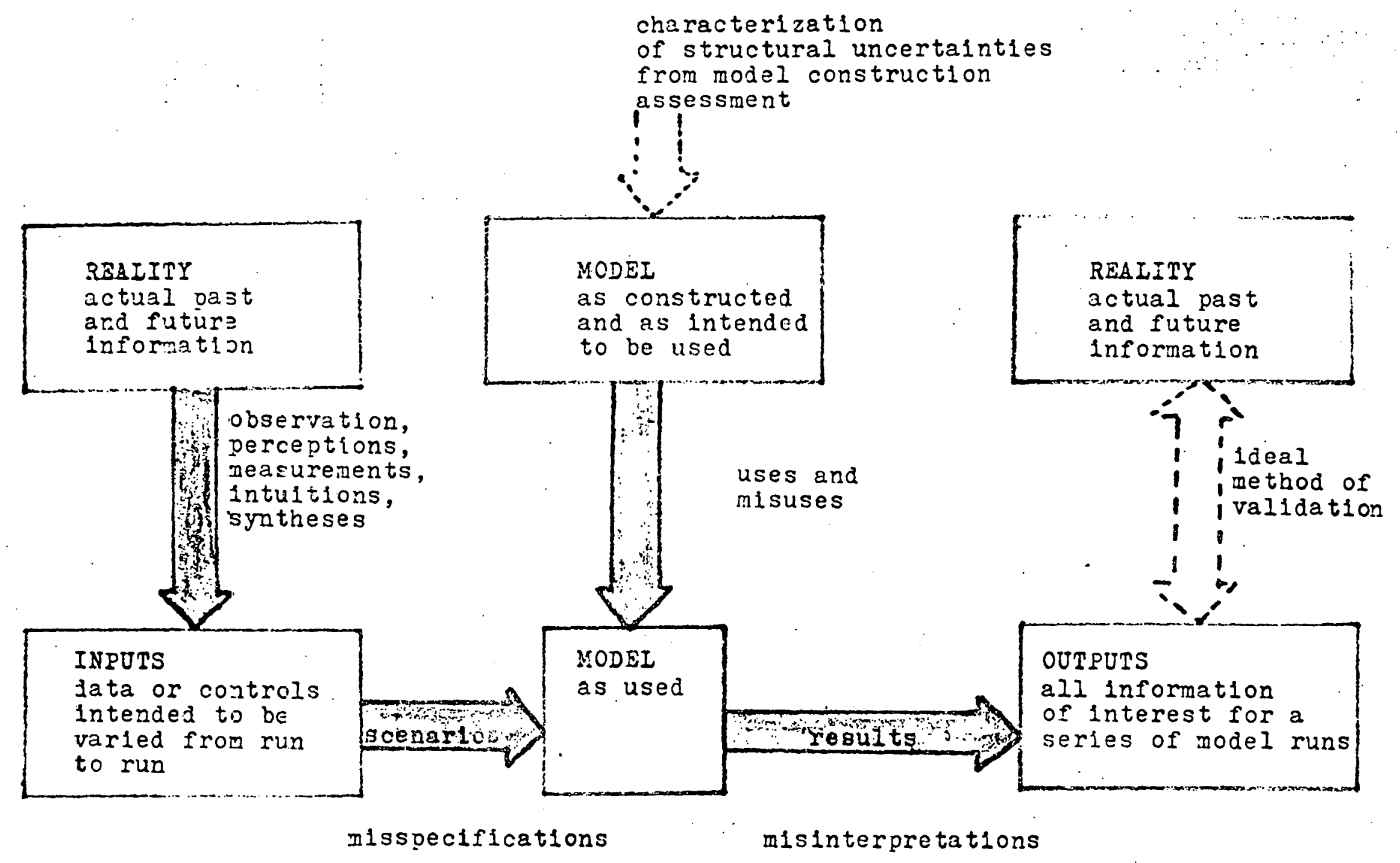

Figure 5 TYPES OF UNCERTAINTIES INTOLVED IN MODEL USE 
When such a comparison is not possible, there is no other evaluation al ternative possible except to trace backward through all the other sections of Figure 6 , checking all of the phases of model use and development. The most systematic procedure for such assessments is to trace the historical tract of model development and use. This is true for models in development phases as well as for mature models. Obviously if a model is being constructed there is additional evaluation information available:

(1) the model constructors can be questioned about decisions at a point in time closer to their original thought processes,

(2) additional documentations may be stimulated, and

(3) feedback of evaluation ideas is more likely to effect the construction of the model, both due to expediencies and to the lesser extent of model builder ego identification with the model in its earliest stages.

The question now arises as to what the appropriate types of assessment are at the various stages of model development. Figure 6 shows some types of assessment activities that can be associated with the previousiy described stages of development. Each of these activities is an attempt to probe for the existence and extent of corruptions that have taken place in the actualization of the model. For example, consider the first step in the model development process, the transfer from motivation to conceptualization. In drawing the free-body diagram around the effects and variables that would be included in the model, the builder has made assumptions about endogenous, exogenous, and untreated effects. These assumptions can conceptually be treated by examining one more layer of detail around the free-body diagram, in other words, stepping back and taking a more universal or global perspective. Figure 7 shows some of the analogous assessment activities that can take place during the model application process. The following section contains discussions of just how such assessment activities might be implemented and orchestrated.

\subsection{Implementation of Developmental Assessment}

The crucial issue in the implementation of this type of "on-line" assessment is the selection of the points for passing batches of information from the modelers to the assessors. In the absence of specific concerns about a particular selection strategy it would seem 


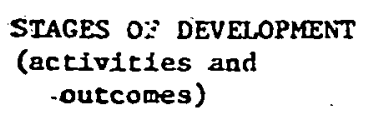

KOTIVATION

CONCEPTDALIZATION

RESEARCH PLAN

DOP.IRICAL RESEARCH

IUTPLEMENTATION

ASSESSMENT
DEVELOPMENT PROCESS

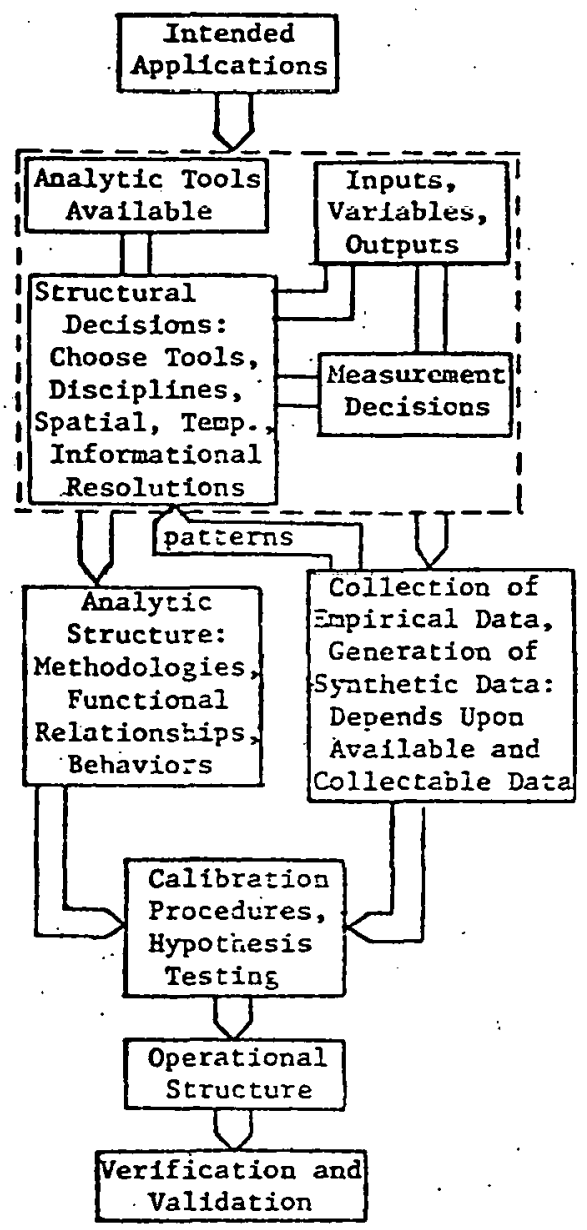

ASSESS LENT .APPROACF IS AND .. TECHN! QUES

Glo sal . Perspective

Data Error
Estimation

CounterModeling,

-Respecification

Aggregation, Disaggreg.

Data Splitting, Measures of Fit, Ridge Regression, Sensitivity of Fit, Check Against New Data

Comparison with

Structures of Other Models

Structural Error. Estimation

\section{DOCUMENTATIUN \\ IDEAL FOR \\ ASSESSMENT}
-Actual, Intended and Potenclal -Applications

- Motivations and Objectives of Modeling Effort

- Modeling Approach, Scope, Iisclp- lines, Assumpt.

-Implementation PIan and ObjectIves (Extent of - Portabllity,etc)

-Research Plan Forunulation, Measurement Hypotheses Maintained to Be Tested

-Display and JustIfy the Data

-Research Results

-Implementation System Descript. : (Algorithms, etc) Operator Guides, User Guldes, Test Problems

-Implemented Model Computer coje

Figure 6 Steps in the Process of Model Development, From Ideal to Actual, and Potential Points (Arrows) of Corruption of the Procedure 
STAGES OF APPLICATIO:

(activities and outccmes)

MOTIVATION

CONCEPTUALIZATION

IMPLEMENTATION

INTEPPRETATION

ASSESSMEN'T
UTILIZATION PROCESS

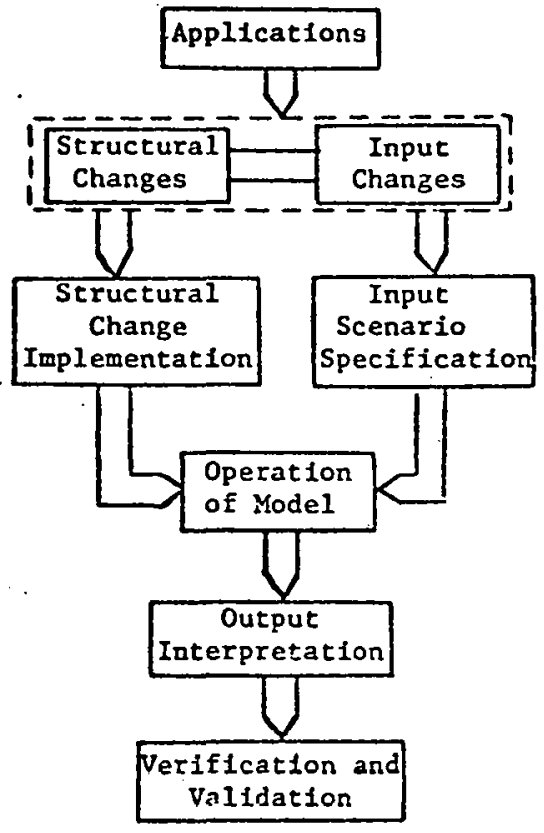

ASSESSMENT
APPROACHES AND
TECHNIQUES
Collection of
Poteatial Policy
dctlons and Model
Uses - Motivate
Experiments
Evaluate the
Measurement Errors
and Input
Uncertalnties
Incorporate
Analyses of
Structural
Uncertainties
Propogate
Input and
Structural
Uncertaintles
Through Model
Validity of
Interpretations
Assess Predictive
Quality, Evaluate
Thoroughness of
Validation Procedures

DOCUMENTATION

IDEAL FOR ASSESSMENT

-I1sts of Valfd Applications

-Motives and Data Behind Changes

-Exact Scenario and Structural Specification

-Machine Environment and Procedures Used

-Results, Both Raw and Interpreted

-Val1dailon Procedures Used.

Figure 7 Steps in the Process of Using a Model, From Ideal to Actual, and Potential Points (Arrows) of Corruption in the Utilization Procedure 
appropriate to have six exchanges of information, after the completion of each of the six phases of model development shown back in Figure 3. other strategic information that is specific to each model and.would have an.important bearing on the selection of "assessment points" includes:

(1) perceived importance of the model,

(2) anticipated development time for each of the stages,

(3) model size and complexity,

(4) use of mature subcomponents, and the assessment history of those components, and

(5) use of existing data bases, and the assessment history of those data.

Given these types of information the strategy for assessment involves making a series of decisions about assessment objectives, setting, depth, and scope at each of the development stages, and these are now briefly discussed.

In order to make choices between al ternative assessment paths, the objectives or goais of the assessment must first be clearly understood. Some possible objectives include:

(1) validate specific past applications,

(2) validate generic future applications,

(3) suggest model improvements,

(4) create a resource group having expertise on the model,

(5) establish credibility amung user's,

(6) test transferability or usability by others, and

(7) further the state of the art of model assessment.

The most obvious, and perhaps best defined, of these objectives is the validation of the input data and structural form of the model relative to specific applications. It would probably be more useful to make statements about the appropriateness of a model for contributing information to future policy decisions in generic application areas. Two objectives that would be difficult to achieve simultaneously would be (1) suggestions for mudel improvements, and (2) establishing model credibility. The first of these suggests a series of model versions, while the second suggests a single model version established at the beginning of the assessment. 
Once the objectives have been decided, there are a number of a) ternative settings and depths for the assessment process. Some of these alternatives result from the possibility of different assessor identities. For example, the assessors could be any of the following:

(1) model builder,

(2) model sponsor,

(3) independent third-party,

(4) several model builders, such as a forum, or

(5) several third-party assessors.

In addition, the assessors could address either a single model or several comparable models. There could be very different expectations from the assessment process depending upon this choice of setting. For instance, the model builder could obviously provide a very cost-effective assessment, but credibility would be difficult to establish under such circlims tances.

For each possible assessment setting outlined above there are four potential depths:

(1) literature review: survey and critical analysis of the published literature on the structure, implementation, and applications of one or more models;

(2) overview: literature review plus analysis of computer codes and other unpublished materials;

(3) independent audit: overview plus the conduct of model exercises designed by the assessor and executed by the modeler with the assessor "looking over the shoulder;"

(4) in-depth: independent detailed assessment of model

formulation, structure, and implementation with the assessor in control of the model and associated data base.

The most cost-effective of these depths will depend upon a number of model characteristics, most particularly, model maturity. If a model is very mature, it is probably worthwhile to go to the expense of an in-depth assessment. If it is immature, then an audit or overview might be sufficient for reaching major conclusions. Size, structure, complexity, execution costs, previous applications, and previous assessments are all aspects that should contribute to the decision on the 
most cost-effective depth. It might be noted that the classical validation process has consisted of in-depth assessment by model builders, audit roles for model sponsors, and literature review or. peer review by independent parties.

As has been pointed out by Saul Gass in several of his papers, an important way to limit the assessment process is to limit its scope (see Table 1). First, decisions must be made concerning the version(s) of the model that is to be assessed, and the types of model applications at which the assessment process is to be aimed. Point 2 of Table 1 defines different aspects of the model that can be evaluated in an assessment: documentation, validity, verification, or operational characteristics.

The product of all these considerations should be in the form of assessment and documentation strategies. Table 2 illustrates the strategic possibilities. These strategies, and associated schedules, should be decided before the development, or redevelopment, of a model and should be agreed to by builder, sponsor, and assessor. 
Table 1

\section{Scope of the Assessment}

1. Specific Applications of Interest

1.1 Validation in context of specific applications, ranges of variables, degree of aggregation reguired, absolute values versus policy perturbation studies

1.2 No specific cases, just an assessmerit that provides the foundation for generally evaluating model accuracy

2. Aspects to be Assessed

2.1 Documentation- of structure, validations performed parameter estimation, past uses, applicability, computer code and use

2.2 Validity - informed judgment about model logic and empirical content

2.2.1 Data or input validity - empirjcal implenentation, quality of updating procedure

2.2.2 Logical or structural validity

2.2.3 Predictive or output validity

2.3 Verification - accuracy of algorithmic and computational implenentation

2.4 Operational characteristics - flcxibility, extensibjilty, trarsferability (training required, ease of use, modeler independence from model and model knowledge), time and cost efficiencies 


\section{Model Development}

\section{Analysis of policy} research needs

Structural analysis, comparison of methodalogies, anatysis of associated measurement issues.

Integration of known resuits with policy research needs

\section{Measurement; data} collection and generation

\section{Empirical research}

Implementing model

\section{Modeling rational, objectives, implemertation olan}

Model formulation and empirica? research plan

Associated data base

Research results

Operational model

\section{Counter analysis, evaluation}

\section{Counter analysis, evaluation, literature review}

\section{Evaluation, literature review}

Evaluation, literature review, overview, independent audit, counter modeling

Evaluation, literature review, overview, independent audit, counter modeling, in-depth
Independent opinion

Independent opinion, structural validity

Independent opinion, content validity

Independent opinion, validity

structural

content

predictive

Independent opinion validity

structure content predictive Verify implementation, useability 


\subsection{Survey of Model Evaluation Studies}

In previous sections we have mentioned a number of policy model evaluation projects. We now turn to a nonsystematic survey and classification of these studies employing the taxonomy of validation and verification elements developed in Section 3.2. Table 3 summarizes the various energy model evaluation projects in terms of approach and emphasis.*

A significant number of energy model evaluation studies based upon review of published literature and applications have been conducted. The style and focus of these studies are diverse ranging from comparative analysis of selected models against structural and content criteria derived from theoretical analysis (e.g., Taylor [1975]) to reviews of model-based applications with only secondary attention to model evaluation (e.g., Gordon [1977]). Further, many of these studies include several models, and so have considerable value in providing introduction to the models and interpretive material relating to their use.

Brock and Nesbitt (1977) have reviewed six large-scale energy planning models. The study provides a detailed development of economic equilibrium concepts, as well as interpretive information on each of the models. The study provides less information on the appropriate application areas for each of the models.

Richard Gordon (1977) has undertaken a series of reviews of existing coal studies for EPRI which include evaluation of models, as well as model results. These reviews provide an important source of information on comparing coal supply and use models. Because of their lucid presentation, these reviews are accessible to a wide audience.

Taylor (1975) has conducted a review of eleven econometric models of electricity demand. This study is most interesting in that it provides a paradigm for comparative evaluation of models against criteria based upon theoretical analysis. Taylor analyzes a system characterized by

\footnotetext{
*The studies summarized are those with which we are familiar and the classification is based upon our analysis of the study reports with, in some cases, the benefit of discussion with the model analyzers. However, I am certain that some studies which should have been included are omitted due to ignorance, and the characterization of emphas is is not likely to always correspond with what the analyst intended.
} 
TABLE I

Classificaticn of Energy Model Assessment Projects by Approach, Emphasis, and Primary Audience

\begin{tabular}{|c|c|c|c|c|c|c|c|c|c|c|}
\hline Assessment Project & $\begin{array}{l}\text { Assessor' } \\
\text { Sponsor }\end{array}$ & $\begin{array}{l}\text { Assessment } \\
\text { Approachl }\end{array}$ & $\begin{array}{l}\text { Primary } \\
\text { Audience }\end{array}$ & \multicolumn{3}{|c|}{ Model Validity - } & $\begin{array}{c}\text { Associated } \\
\text { Data }\end{array}$ & $\begin{array}{l}\text { Verification } \\
\text { of Implementation }\end{array}$ & \multicolumn{2}{|c|}{ Usability } \\
\hline $\begin{array}{l}\text { Mcthodolog cal Review } \\
\text { of Six Large-Scale } \\
\text { Encrgy Planning Models } \\
\text { [3] }\end{array}$ & $\begin{array}{l}\text { Brock- } \\
\text { Nesbitt/ } \\
\text { NSF }\end{array}$ &.$L R$ & $p$ & $\checkmark$ & . & & & & . & \\
\hline $\begin{array}{l}\text { Methodological Review } \\
\text { of Existing Coal } \\
\text { Studies [2G] }\end{array}$ & $\begin{array}{l}\text { Gordcn/ } \\
\text { EPRI }\end{array}$ & LR & A & & $\checkmark$ & . & $\checkmark$ & & & . \\
\hline $\begin{array}{l}\text { Metrodologicel Review } \\
\text { of Electricity Demand } \\
\text { Modeis [E4] }\end{array}$ & $\begin{array}{l}\text { Taylor/ } \\
\text { EPRI }\end{array}$ & LR & A & & $\checkmark$ & & & & & \\
\hline $\begin{array}{l}\text { Methodologicä Review } \\
\text { of Energy [enand } \\
\text { Models [31] }\end{array}$ & $\begin{array}{l}\text { Hartman/ } \\
\text { Research }\end{array}$ & LR & $p$ & $r$ & 1 & & & & & - \\
\hline PIES [47] & $\begin{array}{l}\text { MIT E-Lab/ } \\
\text { NSF }\end{array}$ & IA & A & $\checkmark$ & $\checkmark$ & & r & & & ज़ \\
\hline PIES [1] & $\begin{array}{l}\text { Battelle } \\
\text { Inst./NSF }\end{array}$ & IA & A & i & $\checkmark$ & & $\checkmark$ & & & \\
\hline PIES [26] & $\begin{array}{l}\text { GnO/ } \\
\text { Congress }\end{array}$ & LR & 0 & r & $\checkmark$ & & & & & \\
\hline PIES [32] & $\begin{array}{l}\text { Hausman/ } \\
\text { Research }\end{array}$ & 0 & $P, A$ & $\checkmark$ & $\checkmark$ & & 1 & & & \\
\hline PIES [39] & $\begin{array}{l}\text { RFFI } \\
\text { FEA }\end{array}$ & 0 & $P, A$ & $\checkmark$ & $\checkmark$ & & $\checkmark$ & & & \\
\hline PIES [55] & $\begin{array}{l}\text { Optional } \\
\text { Analysis } \\
\text { Co./Congres }\end{array}$ & $5 s$ & 0 & i & . & & & & & \\
\hline $\begin{array}{l}\text { Review of iarge-Scale. } \\
\text { Energy Models [5] }\end{array}$ & $\begin{array}{l}\text { CRM } \\
\text { EPRI }\end{array}$ & LR & $\mathrm{P}, \mathrm{s}$ & $\checkmark$ & 1 & & & & & \\
\hline PIE: [35] & TEAC/ & I & $P, A, D$ & r & $r$ & & 1 & & & \\
\hline
\end{tabular}


TABLE I (continued)

\begin{tabular}{|c|c|c|c|c|c|c|c|c|c|c|c|}
\hline \multirow{2}{*}{ Assessment Project } & \multirow{2}{*}{$\begin{array}{l}\text { Assesscr/ } \\
\text { Sponsor }\end{array}$} & \multirow{2}{*}{$\begin{array}{l}\text { Assessment } \\
\text { Approach }\end{array}$} & \multirow{2}{*}{$\begin{array}{l}\text { Primary } \\
\text { Piddience }\end{array}$} & \multicolumn{3}{|c|}{ Model Validity } & \multirow{2}{*}{\multicolumn{2}{|c|}{$\begin{array}{c}\text { Associated } \\
\text { Oata }\end{array}$}} & \multirow{2}{*}{$\begin{array}{c}\text { Verification } \\
\text { of Implementation }\end{array}$} & \multicolumn{2}{|c|}{ Usabtlity } \\
\hline & & & & Structure & Content & Prediction] & & & & Documentation & |Efficiency \\
\hline $\begin{array}{l}\text { Comparative State-of-the- } \\
\text { Art Assessment: of Gas } \\
\text { Supply Model ing [43] }\end{array}$ & $\begin{array}{l}\text { Matritech, } \\
\text { Inc./E?RI }\end{array}$ & $L R$ & $P, A, S$ & $!$ & & & & & & & \\
\hline $\begin{array}{l}\text { Comparative State-of-the- } \\
\text { Art Assessment of 0it } \\
\text { Supply Modeling [44] }\end{array}$ & $\begin{array}{l}\text { Mathtech, } \\
\text { Inc./EPRI }\end{array}$ & $L R$ & $P, A, S$ & $r$ & & & & & & & \\
\hline $\begin{array}{l}\text { Review of Encrgy Models } \\
\text { Relating to Enployment } \\
\text { and Manpower /nalysis [11] }\end{array}$ & $\begin{array}{l}\text { Eckstein- } \\
\text { Heien/DoL }\end{array}$ & $L R$ & $P, A$ & 1 & 1 & . & & . & & & \\
\hline $\begin{array}{l}\text { Strategic Environmental } \\
\text { Assessment Sy!:tem [59] }\end{array}$ & $\begin{array}{l}\text { Panel/ } \\
\text { EPA }\end{array}$ & $L R$ & $s$ & & $f$ & & & & & & \\
\hline $\begin{array}{l}\text { Brooihaven Enurgy } \\
\text { System Optimi::ation } \\
\text { Model [85] }\end{array}$ & $\begin{array}{l}\text { Wood- } \\
\text { Hausman/ } \\
\text { EPRI }\end{array}$ & LR & & $\therefore$ & $\checkmark$ & & $\cdot$ & & & . & 8 \\
\hline $\begin{array}{l}\text { Regional Econumic and } \\
\text { Deniographic Mndel } \\
\text { (see Freedman [20]) }\end{array}$ & $\begin{array}{l}\text { Expert } \\
\text { Panel/ } \\
\text { EIA }\end{array}$ & $L R$ & $P, A, S$ & $r^{\prime}$ & $\checkmark$ & & $y$ & . & & & \\
\hline $\begin{array}{l}\text { Comparative Assessnent } \\
\text { of Three } 0 i] \text { ic Gas } \\
\text { Mcdels [56] }\end{array}$ & $\begin{array}{l}\text { Pindyck/ } \\
\text { NSF }\end{array}$ & $I$ & $p$ & $r$ & 1 & $r$ & & & . & & \\
\hline $\begin{array}{l}\text { Wharton Annua Energy } \\
\text { Model [45] }\end{array}$ & $\begin{array}{l}\text { MITI } \\
\text { EPRI }\end{array}$ & IA & $M, S$ & $s^{\prime}$ & $\checkmark$ & & & & & & \\
\hline $\begin{array}{l}\text { Conparative Assessment } \\
\text { of MacAvoy-Pilldyck and } \\
\text { TERRA Natural Gas } \\
\text { Industry Mode is [50] }\end{array}$ & $\begin{array}{l}\text { Neri/ } \\
\text { FEA }\end{array}$ & I & $p$ & 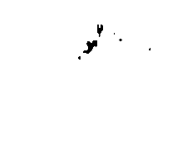 & & $\checkmark$ & & & & . & \\
\hline $\begin{array}{l}\text { Brookhaven Energy } \\
\text { System Models } \\
\text { (EESDM, DESOMi [63] }\end{array}$ & $\begin{array}{l}\text { SCII } \\
\text { EPRI }\end{array}$ & I & $P, S$ & $r$ & 1 & & & & & & \\
\hline
\end{tabular}


TABLE 1 (continued)

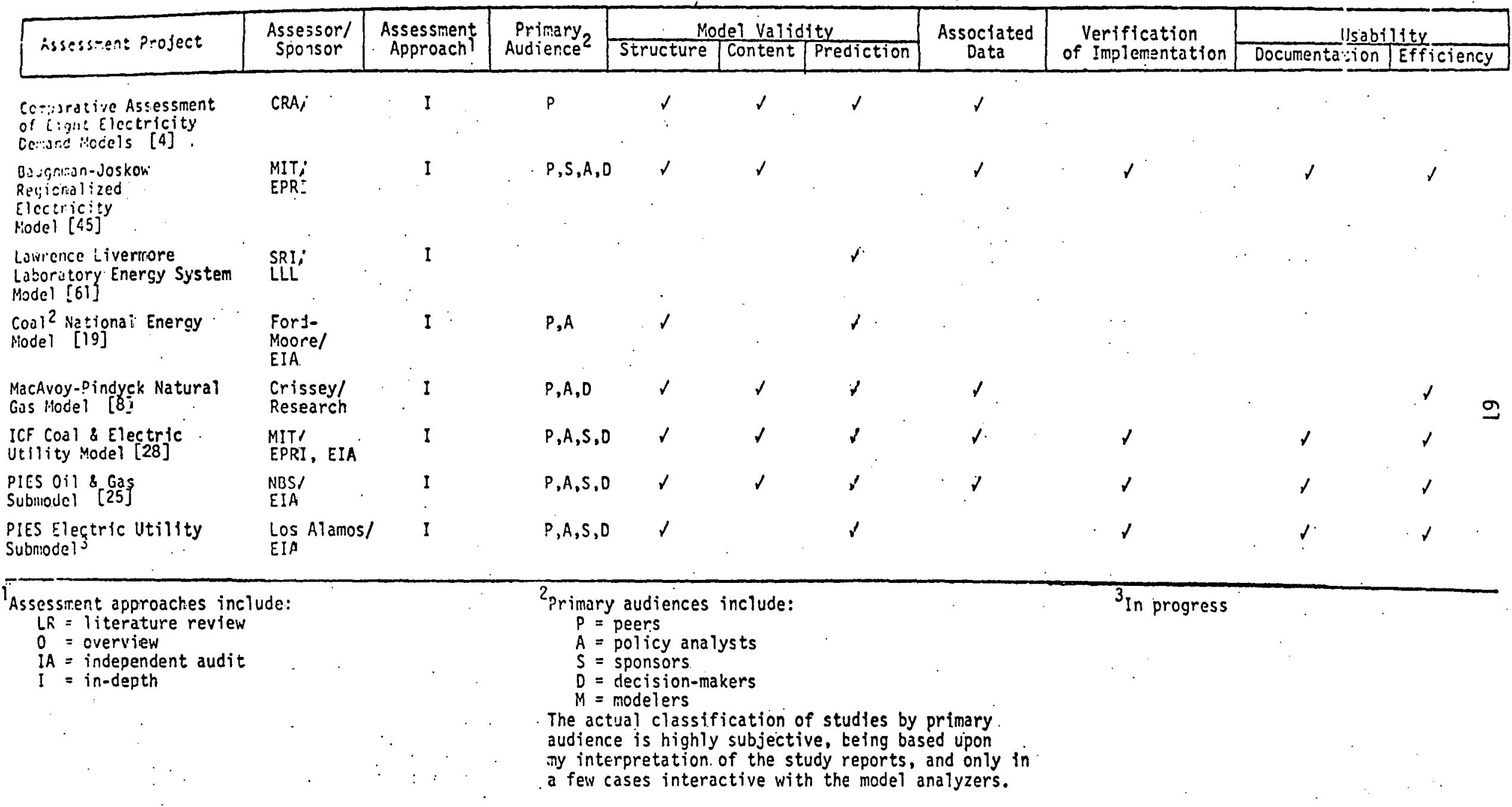


regulation and decreasing block pricing. The analysis identifies concepts and variables which he argues must be considered in any model of electricity demand. Comparing the models under investigation against this standard, he finds that all are deficient respecting treatment of decreasing block pricing. He proposes an "essentially correct alternative" which he and his colleages have pursued (Data Resources, Inc. [1977]). This study is an important example of the potential importance and power of the literature review approach for comparative model evaluation.

Hartman (1979) provides a methodological review of energy demand models similar in style to that of Taylor (1975). Through analysis, he identifies three characteristics which should be treated separately in any long-run energy demand model. These include the demand for energy-related services, the demand for durable goods to combine with energy forms to satisfy energy-related service demands, and the efficiency of energy use of the durable goods. Hartman also emphasizes the importance of modeling approaches which permit the inclusion of new technologies for providing energy services. In comparing existing models with these criteria, Hartman concludes that current efforts fall short of the standard. He then sketches the theoretical and data developments required to improve existing models.

The Project Independence Evaluation System (PIES) is perhaps the most assessed and evaluated energy policy model in existence, and many of these evaluations have employed the literature review approach. The model was first evaluated following the 1974 publication of the Project Independence Report by the M.I.T. Energy Laboratory Policy Study Group (1975), the Battelle Memorial Institute (1975), the General Accounting Office (1975), and Hausman (1975). The M.I.T., Battelle, and Hausman studies are all based upon the Project Independence Report and associated materials, and emphasize analysis of model structural characteristics and plausibility of results.* The GAO study, commissioned by Congress, summarizes the results of the other studies and provides perspective and interpretive material for Congressional decision makers.

*The M.I.T. study also made use of some additional runs by FEA conducted to resolve some issues relating to performance of the PIES oil and gas submodel, and so is an instance of the independent audit approach. 
Following publication of the National Energy Outlook in 1976 (Federal Energy Administration [1976]), the FEA sponsored an evaluation of the revised PIES conducted by Resources for the Future (Landsberg [1977]). RFF organized their evaluation of PIES by convening working groups of independent experts primarily from universities. The focus of evaluation was based upon the published literature and followed the general style of the earlier Battelle and M.I.T. evaluations. However, the use of independent experts from a variety of organizations was unique to. this assessment and seems to have been effective both in venting the model and model applications to a wide audience of scholars and in obtaining a comprehensive critical evaluation.

A second evaluation of the revised PIES model used in support of NEO-76 was commissioned by the House Subcommittee on Energy and Power and was conducted by Optimal Analysis Co. (1976). Their rather brief report focused upon the completeness of PIES to support policy decisions, and proposed new modeling efforts emphasizing dynamics of transition to new fuel forms and "crisis" (i.e., embargo) analysis.

The most recent non-EIA-sponsored assessment of the PIES modeling system (now called the Mid-Term Energy Market Forecasting System) has been sponsored by the Texas Energy and Natural Resources Advisory Council (TENRAC). This evaluation, the Texas National Energy Modeling Project, involves an in-depth analysis of the component models of PIES by various research groups located in the Texas university system. The project has involved transporting the PIES system and associated data base to the computer center at Texas $\Lambda \& M$, and replicating previous EIA analyses. In addition, the model's documentation and computer code are the raw materials for an in-depth, independent evaluation. Sensitivity experiments and the results of structural changes are being investigated. The results of this evaluation are available, and provide an important source of information on the validity of the PIES component models and on the accuracy of implementation (Holloway [1980a]). In contrast to the previous assessments of PIES, which were in the nature of literature review and overview analyses, the TENRAC evaluation examines the PIES implementation.* 
Charles River Associates, Inc. (1979) has recently completed a review of 14 energy system models. The focus of the review is on the applicability of each model to particular analytical and policy research. issues of importance to EPRI. Including fuels for generation, electricity supply, electricity use, and the environmental aspects of decisions in these three areas. The review emphasizes description and analysis of model structure and content, and in some instances provides important interpretive information not readily available from the model documentation. The report also includes a general discussion of selected model issues (see Section 5).

Mathtech, Inc. (1977) has conducted a comparative assessment of twelve models of natural gas supply. Three model types are distinguished including structural, econometric, and resource base-geologic, al though the overlap between these various modeling approaches is acknowledged, especially in specific model descriptions and evaluations. The report provides a survey of the natural gas supply process and a general discussion of the history of modeling for this industry. Each model is described in terms of a common set of descriptors, as well as in detail, and major applications are reviewed and analyzed. The report emphasized comparative description of models, not critical evaluation, and is somewhat similar in style to the effort of Brock and Nesbitt (1977). A similar effort was conducted by the same authors for oil supply industry models (Mathtech, Inc. [1978]).

Eckste in and Heien (1978) have conducted a review of most of the "active" energy models with specific attention to their potential for use in employment and manpower analysis. The review is based upon analysis of technical documentation and applications, and selected interaction with the modelers. The study distinguishes three periods for analysis including post-embargo shock effects, intermediate term adjustment, and long-run equilibrium. Models are classified into three groups including energy/economy, energy sector, and energy subsector models. The focus of the review is on the structural characteristics of each model's treatment of the interactions between employment and energy use. The issues and comparative model capabilities are well developed and presented in an even-handed manner. 
In 1975 the Environmental Protection Agency sponsored an evaluation of the Strategic Environmental Assessment System (SEAS [1975]), a major environmental policy analysis model with important interactions with the energy sector. The assessment was conducted by a panel of experts under the chairmanship of Wassily Leontief. This assessment provides the first example I have found of an assessment project for an important energy-related policy model using outside experts.

In 1975 Wood and Hausman (1975) conducted an assessment of the Brookhaven Energy Systen Optimization Model (BESOM) under the sponsorship of the Office of Technology Assessment. The purpose of this assessment was to comment upon the appropriateness of BESOM in its applications in support of the first National Energy Research and Development Plan. The assessment was based upon the documentation of the applications, as well as the model documentation, and concluded that the model was appropriate for the applications undertaken by ERDA, but should be extended to provide for interfactor substitution between energy and other inputs, and more direct links between the energy system and the macroeconomy.

EIA sponsored an evaluation of the Regional Energy Activity and Demographic Model (READ).* The evaluation was conducted by a panel of independent experts and consultants, primarily from universities. The assessment is based upon the available documentation for the model, as well as interaction between the evaluation panel and the modelers, all of whom are EIA staff members. Technical aspects of the assessment are discussed in the paper by Freedman (1980).

Pindyck (1974) has conducted a comparative assessment of three oil and gas supply models including the MacAvoy/Pindyck National Gas Industry Model, the FPC-Kazzoom National Gas Supply Model, and the Erickson/Spann National Gas Supply Model. Pindyck reestimates the three models with a common data base and estimation procedure, and with the minimum possible structural changes necessary to put the models on a common basis. He then uses each model integrated in to a complete supply/demand model to compare the regulatory policy implications of each formulation.

\footnotetext{
*No formal report of this assessment was published, al though various materials relating to the organization and results of the project are available from EIA's Office of Analysis Oversight and Access.
} 
The policy implications of the different models are quite diverse, indicating that at least among these three models no consensus exists as to how gas supplies will respond to price increases. The Pindyck study is an important example of in-depth comparative evaluation.

As part of its model evaluation activity for EPRI, the M.I.T. Energy Laboratory undertook an independent audit of the Wharton Annual Energy Model (M.I.T. Energy Model Analysis Program [1979]). At the time of the study, only a prototype version of the model was available, and little documentation existed. The study consisted of setting up a series of computational experiments in which the expected performance of the model was hypothesized. The computational experiments then served to confirm these hypotheses, and/or to provide material for analysis of model behavior.

Neri (1975) has conducted a most interesting comparative assessment of the MacAvoy/Pindyck Natural Gas Industry Model and the American Gas Association Tera Model. Neri focused on developing simulations from the two models which were normalized to the greatest extent possible respecting input data. He then analyzed the model data and structure in an effort to explain the differences in the two forecasts, and provides a detailed reconciliation of the simulations expressed in terms of differences in model data and structure. The study is an excellent example of comparison of models with differing structures, associated. data, and methods for estimating structural parameters.

Systems Control Inc. (SCI) (1978) has recently completed an in-depth assessment of the Brookhaven Energy System Optimization Model (BESOM), and the Dynamic Energy System Optimization Model (DESOM). The objectives of the SCI study were to analyze the potential of these models for $R D$ planning in the electric utility industry, and to implement specific modifications to improve model performance. Thus the study had a dual objective of evaluation and modeling.

Charles River Associates (CRA) (1976) has conducted a study evaluating eight econometric models of electricity demand. Their approach is as follows: "Each model is replicated, reestimated on a common data set and tested for performance; forecast and backcast accuracy; parameter stability over time; robustness of parameter estimates to small changes in specification or variable measurements, 
consistency and plausibility of model results, and quality of model test statistics" (Charles River Associates [1976], p. iii). The study represents a major effort in putting models on a comparable basis in terms of data and estimation procedures, while preserving original structural specifications. The study results are complicated and difficult to summarize. However, the study represents a major accomplishment in comparative model analysis.

The M.I.T. Energy Model Analysis Program (1979) has conducted an in-depth evaluation of the Baughman/Joskow Regionalized Electricity Model. The study focuses upon the model applications proposed by the modelers or likely to be considered by potential users, and attempts to evaluate the models likely success in supporting these policy analysis applications. The documentation of the evaluation is organized so as to satisfy the interests of scientists, policy analysts and decision makers. In addition to evaluating model validity and verifying implementation, the study assesses the usability of the model and includes recommendations for improving documentation and user efficiency.

Ford, Moore, and McKay (1979) have recently completed an evaluation of the COAL2 National Energy Model. Their study emphasizes the application of methods to analyze the implications of uncertainties in input data and parameters upon output variables. The study does not provide much information on model validity beyond that al ready provided in the model documentation.

An especially interesting example of a modeler/user policy model evaluation is a project at Lawrence Livermore Laboratory (LLL). In a separate effort LLL has transferred, adopted, and reprogrammed the Gulf-SRI Energy System Model (now the LLL Economic Modeling System) (Short et al. [1980]). In an effort to gain understanding of the model's predictive capacity, SRI and LLL have set up an associated data base for the period 1950-1975, and simulated the model over that period for the purpose of analyzing its predictive performance. This effort is especially noteworthy in that the model structure is based primarily upon analysis of engineering and economic data, on submodels of engineering processes, and on analysis of energy industry expansion and operating plans. Typically it has been argued that historical simulation for such 
models is very complicated, if not impossible, because of the difficulty in obtaining historical data, especially industry plans and expectations data, which are independent of subsequent events. The SRI/LLL effort thus represents a major undertaking, and is of interest, both as to what is learned about model performance and what is learned about prediction analysis of engineering process/energy system models.

Crissey (1975) has conducted an evaluation of the MacAvoy/Pindyck Natural Gas Model to illustrate various concepts he has formulated regarding the usefulness and effectiveness of models in the policy research process. Crissey formulates a statement of structural features expected in a model of the natural gas industry to be used in analyzing such policies as price deregulation. Separate lists of characteristics for policy analysis capabilities and instruments are developed, and an analysis of the policy debate is undertaken to identify contention points. All this information is then used to distinguish and analyze the model's contention points. In addition, Crissey makes a separate contribution in demonstrating that the MacAvoy/Pindyck model can be $\therefore$ greatly simplified through certain approximations and aggregations, which have little effect upon predictive behavior.

Finally, the EIA Office of Analysis Oversight and Access has sponsored a number of model analyses; these include the Mid-Term Energy Forecasting System (MEFS) oil and gas submodel (evaluated by NBS), * the MEFS electric utility submodel (evaluated by Los Alamos), and the Coal and Electric Utility Model (evaluated M.I.T.).** These efforts are of special interest because they include the objective of emphasizing all of the dimensions to policy model evaluation identified in Section 3.2.

*See Gass et al . (1980).

**See Goldman (1979). 


\section{Bibl iography}

1. Battelle Memorial Institute [1975], "A Review of the Project Independence Report," Submitted to the Office of Energy Research and Development Policy, National Science Foundation, U.S. Government Printing Office, Washington, D.C., January 10.

2. Baughman, M. and P. Joskow [1976], "The Future of the U.S. Nuclear Energy Industry," in The Bell Journal of Economics, Vol. 7, No. 1, Spring.

3. Brock, H.W. and D.M. Nesbitt [1977], "Large-Scale Energy Planning Models: A Methodological Analysis," Stanford Research Institute, Mento Park, Cal ifornia, May.

4. Charles River Associates, Inc. [1976], "Long-Range Forecasting Properties of State-of-the-Art Models of Demand for Electric Energy," Report Prepared for Electric Power Research Institute, EA-221, Palo Alto, California, December.

5. Charles. River Associates, Inc. [1979], "Review of Large-Scale Energy Models," Report Reported for the Electric Power Research Institute, EA-968, Palo Al to, California, January.

6. Common Cause [1979], "Open for Business Only? A Common Cause Study of the Department of Energy," Washington, D.C.

7. Congressional Quarterly Almanac [1976], U.S. Government Printing Office, Washington, D.C.

8. Crissey, B.L. [1975], "A Rational Framework for the Use of Computer Simulation Models in a Policy Context," Unpublished PhD Dissertation, The Johns Hopkins University, Baltimore, Maryland.

9. Data Resources, Inc. [1977], "The Residential Demand for Electricity," Report Prepared for Electric Power Research Institute, EL-235, Volumes 1 and 2, Palo Alto, Californid, Jalluary.

10. Deeter, C.R., A.A.A. Hoffman, and editors [1978], "Validation of Mathematical Models of Energy-Related Research and Development," Proceedings of an. NSF-Sponsored Conference Held in Dallas, Texas, June.

11. Eckstein, A.J. and D.M. Heien [1978], "A Review of Energy Models with Particular Reference to Employment in Manpower Analysis," Report Prepared for the U.S. Department of Labor, Employment and Training Administration, U.S. Government Printing Office PB-279447, Washington, D.C., March.

12. Energy Information Administration [1978a], Annual Report to Congress, 1977, Volume II, Department of Energy Report No. DUE/EIA-0036-2, Washington, D.C. 
13. Energy Information Administration [1978b], "Memorandum for Applied Analysis Senior Staff," from George M. Lady through C. Roger Glassey, Subject: Interim Model Documentation Standards, Washington, D.C., December 4.

14. Energy Information Administration [1979], Annual Report to Congress, 1978, Department of Energy Report No. DOE/EIA-0T73, in 3 volumes, Washington, D.C.

15. Energy Policy Project of the Ford Foundation [1974], A Time to Choose: America's Energy Future, Ballinger Publishing Company, Cambridge, Massachusetts.

16. Energy Research and Development Administration [1976], "A National Plan for Energy Research Development and Demonstration: Creating Energy Choices for the Future," U.S. Government Printing Office, ERDA 76-1, Washington, D.C.

17. Federal Energy Administration [1974], Project Independence Report, U.S. Government Printing Office, Washington, D.C., November.

18. Federal Energy Administration [1976], National Energy Outlook,

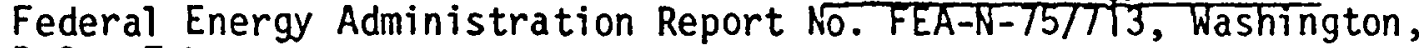
D.C., February.

19. Ford, A., G.H. Moore, and M.D. McKay [1979], "Sensitivity Analysis of Large Computer Models: A Case Study of the COAL2 National Energy Modei," Los Alamos Scientific Laboratory Report No. LA-7772-MS, LoS Alamos, New Mexico, April.

20. Freedman, D. [1980], "Assessing the Regional Energy Activity and Demographic Model," in Validation of Assessment Issues of Energy Modeis, S. I. Gass, (ed.), Proceedings of a Workshop held at the National Bureau of Standards, Gaithersburg, Maryland, January 10-11, 1979, NBS Special Publication 569, U.S. Government Printing Office, Washington, D.C., February.

21. From, G., W.L. Hamilton, and D.E. Hamil ton [1974], "Federal Supported Mathematical Models: Survey and Analysis," National Science Foundation, Washington, D.C.

22. Gass, S. [1977], "Evaluation of Complex Models," in Computer and Operations Research, Vol. 4.

23. Gass, S. [1979a], "Computer Science and Technology: Computer Model Documentation: A Review and Approach," National Bureau of Standards Special Publication No. 500-39, U.S. Department of Commerce, Washington, D.C., February.

24. Gass, S. (ed). [1979b], "Utility and Use of Large-Scale Mathematical Models," Proceedings of Workshop Held at the National Bureau of Standards, NBS Special Publication No. 534, May. 
25. Gass, S., K. Hoffman, R. Jackson. L. Joel, P. Saunders [1980], "The NBS Energy Model Assessment Project: Summary Overview, "Washington, D.C., National Bureau of Standards, U.S. Department of Commerce, NBSIR 80-2128. Report submitted to The Office of Analysis Oversight and Access, U.S. Department of Energy, September.

26. General Accounting Office [1975], "Review of the 1974 Project Independence Evaluation System," Report of the U.S. Congress by the Comptroller General of the United States, U.S. Government Printing office, Washington, D.C.

27. General Accounting Office [1979], "Guidelines for Model Evaluation," U.S. Government Printing Office Report No. PAD-79-17, Washington, D.C., January.

28. Goldman, N.L., M.J. Mason, and D.O. Wood [1979], "An Evaluation of the Coal and Electric Utilities Model Documentation," Report Submitted to DOE/EIA Office of Analysis Oversight and Access, M.I.T. Energy Laboratory Working Paper No. MIT-EL 81-007WP, September.

29. Gordon, R.L. [1977], "Economic Analysis of Coal Supply: An Assessment of Existing Studies," Report Prepared for Electric Power Research Institute, EA-496, Palo Al to, California, July.

30. Greenberger, M., M. Crenson, and B. Crissey [1976], Models in the Policy Process: Public Decision-Making in the Computer Era, Russell Sage Foundation, New York.

31. Hartman, R. [1979], "Frontiers in Energy Demand Modeling," in Annual Review of Energy, Vol. 4.

32. Hausman, J. [1975], "Project Independence Report: An Appraisal of U.S. Energy Needs Up to 1985," in The Bell Journal of Economics and Management, August.

33. Hogan, W.W. [1978], "Energy Modeling: Building Understanding for Better Use," Paper Prepared at the Second Berkeley Symposium on the Systems and Decisions Sciences, Berkeley, California, October.

34. Holloway, M. [1979], "Minutes: Workshop on Substantive Modeling Issues,"Washington, D.C., August 27.

35. Holloway, M. [1980], "The Texas National Energy Modeling Project: An Evaluation of EIA's Mid-Term Energy Forecasting System," in Validation and Assessment Issues of Energy Models, S.I. Gass (ed.), Proceedings of a workshop held at the National Bureau of Standards, Gaithersburg, Maryland, January 10-11, 1979, NBS Special Publication 569, U.S. Government Printing Office, Washington, D.C., February.

36. Holloway, M. (ed.) [1980a], Texas National Energy Modeling Project: An Experience in Large-Scale Model Transfer and Evaluation, Tin 3 volumes). New York, New York: Kcademic Press. 
37. Hudson, E.A. and D.W. Jorgensen [1974], "U.S. Energy Policy and Economic Growth, 1975-2000," in The Bell Journal of Economics and Management Sciences, Vol. 5, No. 2, Autumn.

38. Lady, G. [1979], letter to D.0. Wood, dated May 18.

39. Landsberg, H.H. (ed.) [1977], "Review of Federal Energy Administration National Energy Outlook, 1976," Report Prepared for the National Science Foundation by Resources for the Future, Washington, D.C., March.

40. Logistics Management Institute [1978], "Recommendation for PIES Access," Washington, D.C., March.

41. Logistics Management Institute [1979], "The Integrating Model of the Project Independence Evaluation System, " 6 volumes, Report Prepared for the Energy Information Administration, Department of Energy, U.S. Government Printing Office, Washington, D.C., February.

42. Macrak is, M.S. (ed.) [1974], Energy: Demand, Conservation, and Institutional Problems, The M.I.T. Press, Cambridge, Massachusetts.

43. Mathtech, Inc. [1977], "The Comparative State-of-the-Art Assessment. of Gas Supply Modeling," Report Prepared for Electric Power Research Insti tute, EA-201, Palo Al to, California, February.

44. Mathtech, Inc. [1978], "The Comparative State-of-the-Art Assessment of Oil Supply Modeling," Report Prepared for Electric Power Research Institute, EPRI-EA-609, Palo Al to, California, June.

45. M.I.T. Energy Model Analysis Program [1979], "Independent Assessment of Energy Policy Models," Report Prepared for Electric Power

Research Institute, EA-1071, Palo Al to, California, May.

46. M.I.T. Energy Laboratory Policy Study Group [1974], "Energy Self-Sufficiency: An Economic Evaluation," Report Prepared for the Anerican Enterprise Institute for Public Policy Research, Washington, D.C.

47. M.I.T. Energy Laboratory Policy Study Group [1975], "The FEA Project Independence Report: An Analytical Review and Evaluation," M.I.T. Energy Laboratory Report No. MIT-EL 75-017, May.

48. National Academy of Sciences [1979], National Research Council, Committee on Nuclear and Alternative Energy Systems, Energy in Transition: 1985-2010, W.H. Freeman and Sons, San Francisco.

49. National Bureau of Economic Research, Inc. [1975], "Mode1 Formulation, Validation, and Improvement," Proceedings of an NSF-Sponsored Conference held in Vale, Colorado, June. 
50. Neri, J.A. [1975], "An Evaluation of Two Alternative Supply Models of Natural Gas," in The Bell Journal of Economics, Vol. 6, No. 2, Autumn.

52. Nuclear Energy Policy Study Group [1977], Nuclear Power: Issues and Choices, Ballinger Publishing Company, Cambridge, Massachusetts.

53. Office of Analysis Oversight and Access [1979], Energy Information Administration, "Model Documentation and Archiving: Request for Status Information," Memorandum from N. Dearborn through G. Lady to Applied Analysis Office Directors, October 3.

54. O'Nei11, R.P. [1978], Memorandum to the Record, Department of Energy, Washington, D.C., October 10.

55. Optimal Analysis Company [1976], "A Critique of the Federal Energy Administration's Energy Model," Report Prepared for the U.S House of Representatives Subcomittee on Energy and Policy, Washington, D.C., July.

56. Pindyck, R.S. [1974], "The Regulatory Implications of Three Alternative Econometric Supply Models of Natural Gas," in The Bell Journal of Economics, Vol. 5, No. 2, Autumn.

57. Professional Audit Review Team [1977], "Activities of the Office of Energy Information and Analysis," in Report to the President and the Congress, U.S. Government Printing Office, Washington, D.C., December 5 .

58. Professional Audit Review Team [1979], "Activities of the Energy Information Administration, Department of Energy," in Report to the President and the Congress, U.S. Government Printing Office, Washington, D.C., May T.

59. SEAS Review Panel [1975], "Quality of Review of the Strategic Environmental Assessment Systems (SEAS)." A report to the Executive Cormittee of the Science Advisory Board, U.S. Environmental Protection Agency; December.

60. Shaw, M., J. Farquhar, and S.M. Lutz [1978], "Management and Implementation of PIES Access," and "Recommendations for PIES Access," Reports Prepared for the Energy Information Administration by Logistics Management Institute, Washington, D.C., March.

61. Short, W., J. Rambo, and R. Fuller [1980], "Historical Simulation with the Livermore Economic Modeling System, "Report Prepared by SR I International for Lawrence Li vermore Laboratory, Li vermore, California, January.

62. Stanford Institute for Energy Studies [1977], "Stanford-EPRI Workshop for Considering a Forum for the Analysis of Energy Options Through the Use of Models," Report Prepared for Electric Power Research Institute, EA-414-SR, Palo Al to, Cal ifornia, May. 
63. Systems Control, Inc. [1978], "Applicability of Brookhaven National Laboratories Energy Models to Electric Utility R\&D P1anning," Report Prepared for Electric Power Research Institute, EA-807, Palo Al to, California, June.

64. Taylor, L.D. [1975], "The Demand for Electricity: A Survey, " in The Bell Journal of Economics, Vol. 6, No. 1, Spring.

65. Teitenberg, T.H. [1976], Energy Planning and Policy, Lexington Books, D.C. Heath and Company, Lexington, Massachusetts.

66. U.S. Congress, Public Law 89-487 [July 4, 1966], "Freedom of Information Act," Washington, D.C.

67. U.S. Congress [1974], U.S. Senate, Hearings Before the Committee on Interior and Insular Affairs, "Energy Information Act of 1974," U.S. Goverment Printing Office, Washington, D.C.

68. U.S. Congress, Public Law 93-275 [May 1974], "Federal Energy Administration Act," Washington, D.C.

69. U.S. Congress, Public Law 93-319 [June 1974], "Energy Supply and Environmental Coordination Act," Washington, D.C.

70. U.S. Congress [March 1975a], U.S. House of Representatives, Hearings Before the Subcommittee on Energy and Power, Interstate and Foreign Commerce Committee, "Energy Conservation and Oil Policy, "U.S. Government Printing Office, Washington, D.C.

71. U.S. Congress [March 1975b], U.S. Senate, Hearings Before the Joint Economic Committee, "Reappraisal of Project Independence," U.S. Government Printing Office, Washington D.C.

72. U.S. Congress, Public Law 94-163 [December 17, 1975], "Energy Policy and Conservation Act," Washington, D.C.

73. U.S. Congress [March 3 and 8, 1976], U.S. Senate, Hearings Before the Committee on Interior and Insular Affairs, "The Energy Information Act of 1976," U.S. Government Printing Office, Washington, D.C.

74. U.S. Congress, [March/April 1976], U.S. Senate, Hearings Before the Committee on Government Affairs, "Department of Energy Organization Act," U.S. Government Printing Office, Washington, D.C.

75. U.S. Congress [Apri1 1976], U.S. Senate, Hearings Before the Committee on Government Operations, "Extension of the Federal Energy Administration," U.S. Government Printing Office, Washington, D.C.

76. U.S. Congress [May 3, 1976], U.S. Senate, Hearings Before the Subcommittee on Oversight Procedures, Committee on Government Operations," U.S. Government Printing Office, Washington, D.C. 
77. U.S. Congress [May 10, 1976], U.S. House of Representatives, Committee on Interstate and Foreign Commerce, "Federal Energy Administration Authorization and Extension," Report No. 94-1113, U.S. Government Printing Office, Washington, D.C.

78. U.S. Congress [August 4, 1976], U.S. House of Representatives, Cormittee of Conference, "Federal Energy Administration Authorization and Extension," Report No. 94-1392, U.S. Government Printing Office, Washington, D.C.

79. U.S. Congress, Public 94-385 [August 14, 1976], "Energy Conservation and Production Act," Washington, D.C.

80. U.S. Congress, Pub7 ic Law 94-409 [September 13, 1976], "Government in the Sunshine Act, Washington, D.C.

81. U.S. Congress [May 14, 1977], U.S. House of Representatives, Committee on Governmental Affairs, "Department of Energy Organization Act," Report No. 95-164, U.S. Government Printing Office, Washington, D.C.

82. U.S. Congress [May 16, 1977] U.S. House of Representatives, Committee on Government Operations, "Department of Energy Organization Act," Report No. 95-346, Part 1, U.S. Government Printing Office, Washington, D.C.

83. U.S. Congress [Ju]y 26, 1977], U.S. House of Representatives, Committee of Conference, "Department of Energy Organization Act," Report No. 95-539, U.S. Government Printing Office, Washington, D.C.

84. U.S. Congress, Pubtic Law 95-91 [August 4, 1977], "The Department of Energy Organization Act," Washington, D.C.

85. Wood, D.0. and J. Hausman [1975], "Energy Demand in the ERDA National R,D\&D PIan," in An Analysis of the ERDA Plan and Program, U.S. Congress, Office of Technology Assessment, Washington, D.C. 
APPENDIX A

Origins of Documentation and Public Access Requirements:

An Historical Analysis

by

Martha J. Mason

October 1979

Massachusetts Institute of Technology

Energy Model Analysis Program 


\section{A-2 \\ TABLE OF CONTENTS}

1. Introduction $\ldots \ldots \ldots \ldots \ldots \ldots \ldots \ldots \ldots \ldots \ldots \ldots \ldots \ldots \ldots \ldots \ldots \ldots \ldots$

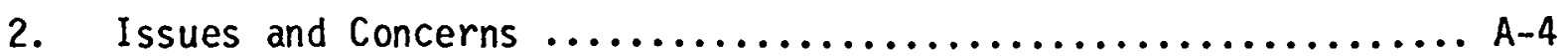

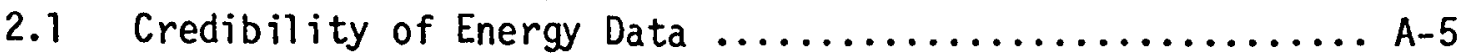

2.2 Analysis of Energy Data $\ldots \ldots \ldots \ldots \ldots \ldots \ldots \ldots \ldots \ldots$.

2.3 Issues in Energy Policy $\ldots \ldots \ldots \ldots \ldots \ldots \ldots \ldots \ldots \ldots . . . \ldots .12$

2.4 Concerns About Computer Modeling ................... A-14

3. Legislation Concerning Energy Information $\ldots \ldots \ldots \ldots \ldots \ldots \ldots$ A-17

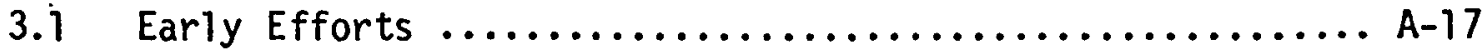

3.2 The Energy Conservation and Production Act ............ A-21

3.3 The DOE Organization Act and Recent Events ............ A-25 
Origins of Documentation and Public Access Requirements:

A Historical Analysis

$1 . \therefore$ Introduction

In the last decade, public access to government operations and documents has become of increasing interest to many Americans. At least in. part growing out of the tumult of the 1960s, the desire for release of government documents has become a trend leading in some cases to direct confrontation between the public and the government, as with the Pentagon Papers and the Nixon tapes. More conventional steps to increase public scrutiny have also been taken including the Sunshine Law of 1976 (U.S. Congress, P.L. 94-409 [September 13, 1976]) and the Freedom of Information Acts (U.S. Congress, P.L. 89-487 [July 4, 1966]).

of more direct interest to the energy information community, hovever, is the subset of the access issue which concerns government access to energy industry information, and in turn, public access to government data and data analysis tools, notably computer models. Since the oil embargo of 1973, the U.S. government has tried to develop systems to accomodate increasing numbers of requests for access to energy information; the creation of various departments within the government to coordinate, maintain, and publish energy information was a first obvious action.

However, the definition of access itself, and appropriate means of supplying that access, are still at issue, and affected agencies (in particular the Energy Information Administration of the Department of Energy) are presently engaged in the process of determining how public access to energy models might best be established. 


\section{A-4}

While the extent to which analytical models become fully accessible to the public will no doubt depend to some degree on the cost and ease of implementation of proposed methods, a policy context for access procedures can be developed by examining pertinent existing legislation and its intent. Pragmatic access practices can then be designed to fall within the scope of that context. As a means of providing such a framework, and in order to understand more clearly the processes that have led to current model assessment and access activities, this paper will first examine the general set of issues and concerns that led to legislative efforts, and then will turn its attention to specific actions

- taken by Congress to address those concerns.

\section{Issues and Concerns}

A survey of the Congressional energy literature produced during the .1970s (including legislation, committee reports and prints, hearings proceedings, and testimony) has indicated that concern during the decade over energy information was widespread among sectors of the public, and was comprehensive in nature. Not only was government use of energy information at issue, but the data itself was considered suspect. In. general, concerns about the energy information fell into four categories:

1) concerns over the credibility of available data,

2) concerns over the analysis of that data

3) concerns about the appropriateness of policy responses to the analysis, and

4) concerns about computer modeling.

The integrity of governmental and corporate dealings was not a new issue when it surfaced with the energy crisis; in fact, it has been a theme 
throughout the development of the American system of democracy. The original three-tiered format of the government, the popular electing of officials, and the antitrust legislation of the turn of the century all were aimed at reducing concentration of power, and maintaining accountability and accessibility of the nations's decision makers. However, during the last decade the issue of accountability arose in a new context. The highly visible profits of the oil companies during a time of energy shortage and the government's use of increasingly complex analytical tools tended to focus attention on concerns about the basis, form, and impact of energy information and policy. In the following sections four substantive components of that concern will be examined in more detail.

\subsection{Credibility of Energy Data}

During the early 1970s there was much discontent over the adequacy of the data upon which U.S. energy policy was ostensibly based. A review of various Congressional hearings held from 1973 to 1977 (see U.S. Congress, "Hearings..."[varfous dates]) has indicated that this concern had several aspects, summarized as follows:

o. Companies (energy producers) were withholding too much information, classifying it as proprietary, and thereby limiting the data with which the government could work.

- The data that the government did have was largely supplied by the energy industry, thereby biasing the data base in favor of industry interests.

- There was a lack of independent verification of industry-supplied data.

- It was impossible to compare the data bases of different agencies because of differences in definitions of the same technical terms (such as "proven resources") and variations in measurement and quantification techniques. 
- Gaps existed in the data, and conflicting statistics were reported at the same time by different agencies (such as the Bureau of Mines and the U.S. Geological Survey).

These complaints addressed the actual condition of the data base upon which any analys is was dependent. Therefore, the development of a complete, accurate, and orderly data base was of the first order of importance.

Specific examples of this kind of concern are extremely numerous, particularly in the wake of the Arab oil embargo of 1973. As Senator John Glenn has pointed out; it was generally recognized that at the time of the embargo no one in the U.S. government was able to accurately state the amount of reserves of oil and gasoline in the United States (U.S. Congress, "Hearings..." [March 3 and 8, 1976]). Indeed, reports were widespread that reserves of gasoline during the shortage were 5 percent higher than normal, as were rumors that tankers full of petroleum were forced to wait off the coast of the United States because there were no storage facilities available at which they could offload their cargo. The General Accounting Office (GAO) in 1976 agreed that much of the rampant public skepticism about government energy pronouncements could be traced to the oil embargo (U.S. Congress, "Hearings..." [May 3, 1976]). A] though four government agencies undertook studies of reserves at that time, the credibility problem was not resolved when those studies were published, even though, according to GAO, most aggregate figures did not differ from those produced by the energy industry by more than about 10 percent. The reason for this lack of credibility was the fact that the reports could not be compared to one another due to disparaties in the format of the data bases.

Public interest groups, such as the Public Citizens Congressional 
Watch and the Environmental Policy Center, echoed these concerns particularly as they reflected on the large extent of government reliance on industry-supplied data, and the need for more disclosure of corporate information (U.S. Congress, "Hearings..." [March 3 and 8; 1976]). For example, Ken Bossong, of the Center for Science in the Public Interest stated the following at hearings held in 1976:

"[Due to] excessive reliance upon energy data supplied by the Nation's oil, coal, natural gas and electric utilities industries, FEA's policies and analyses have... paralleled to a very large degree the views of the companies which the agency is supposed to be watch-dogging" (U.S. Congress, "Hearings..." [Apri1 1976])

One theme, then, was for full disclosure of private industry's data, a theme strongly opposed by most companies and many legislators. The argument for disclosure, however, found a strong advocate in Senator Abourezk of South Dakota (U.S. Congress, "Hearings..." [1974]). While some witnesses at government hearings argued that more complete disclosure of private sector information would not hurt any individual corporation as long as all companies were subjected to the same regulations, Senator Abourezk took a more extreme approach. It was his feeling that the federal government and the energy producers had together "rigged" the energy shortage in order to increase the prices of gas and oil. This distrust led him to argue that all industry information should become public unless the company could prove the need for confidentiality. The companies, not surprisingly, took the opposite stance--that the burden of proving the need for the information rested on the public sector.*

*Senator Abourezk claimed that a precedent supporting his viewpoint had been set in what he called the "landmark decision" of February 4, 1974, in which the Federal Power Commission won the point that ". . The public right to the information outweighs the private proprietary interest" of the energy producers (U.S. Congress, "Hearings..." [1974]). others at these hearings supported this viewpoint, including Senator Gaylord Nel son, and Ralph Nader. 


\section{A-8}

Proponents of disclosure of industry information also pointed to the movement of employees between the large corporations, and interlocking directorates (U.S. Congress, "Hearings..." [1974]). They asked how companes could claim that proprietary information was being kept "secret" from competitors, when a given individual might be sitting on the Boards of Directors of two or more major oil companies simultaneously. While industry representatives and some legislators (including senators Bartlett and Fannin) argued for proprietary protection, Congressional actions subsequently indicated the general support for greater disclosure of industry data in order to improve the government data base (U.S. Congress, "Hearings..." [March 3 and 8, 1976]).

\subsection{Analysis of Energy Data}

A second major set of issues revolved around the analysis of available data. The problem of analysis was in some ways of graver concern than that of insufficient information, because inadequacies of analysis were considered more difficult to detect than inadequacies of data.

In general, critical opinions about government analysis of energy data were grouped as follows:

- the analysts were too closely related to the oil industry to prepare truly independent and objective reports;

- the analysts were under pressure from the Executive Branch to develop data that would support particular policy positions; and

- the assumptions and interpretations that went into the analyses were not distinguishable from the factual bases and were not identified, making replication of results difficult.

In essence, many people wished to insulate analysis activities from outside influences that would deter objectivity. They also demanded 
better documentation of what analytical assumptions had been made, in order to facilitate review and alteration of important inputs.

For example, one complaint was that the government's energy analysts had been "groomed" by the private energy industry prior to joining the public sector, and thus would be biased toward industry viewpoints. While trading of experts between public and private sectors is not uncommon, and can be a positive influence in many ways, the energy debate was highly sensitive to suggestions of bias. (Indeed, this viewpoint still persists as a recent study produced by Common Cause (1979), 1 isting important energy officials and their past employment affiliations, indicates.)

Thus, insulation from industry pressure was a concern. However, an equally strident demand was for insulation from Administrative pressure. Ken Bossong described succinctly what many witnesses at Congressional hearings were indicating about the need for this kind of insulation:

"The responsibility for collecting and analyzing the information upon which FEA bases its pricing decisions should be vested el sewhere. Currently FEA is a captured agency of the White House and its interpretation of given data reflects both the biases of the Administration as well as the priorities of the industries that. supply the data. We believe that information gathering and analysis should be located in a separate agency--possibly one located within Congress." (U.S. Congress, "Hearings..." [April 1976]).

The desire was to assure the nation of accurate basic data on which to base its energy decisions. In order to do this effectively, that data had to be "as independent of political influence as humanly possible" (U.S. Congress, "Hearings..." [March 3 and 8, 1976]).

In February of 1974, William Simon, then the Administrator of the Federal Energy Office, wrote the following in a letter to Senator Gaylord Nelson of the Senate Interior Committee: 


\section{A-10}

"As I indicated in my testimony before your committee, there is an urgent need for a strong and objective Energy Information Center. This office must have the authority to collect a wide range of data including reserves, inventories, production, consumption, cost, pricing, and other energy related information. Legislation is needed to establish the Energy Information Center in the Federal Energy Administration upon passage of its enabling legislation, and to temporarily staff and manage the Center in the FEA ..... Independence and objectivity of the office would be a high priority and would be assured by the release to the public of as much information as possible and the establishment of an independent review group to oversee the office's operations (U.S. Congress, "Hearings..." [1974])."

This kind of strong statement of assurance was specifically intended to quell the fears of non-objectivity in data analysis that had been voiced on nearly every front. However, to many people, merely having a stated assurance was not enough. Ralph Nader, for example, coined the term "simonizing" to describe his opinion of William Simon's ability to sidestep any direct attempt by Congress to force disclosure of information (U.S. Congress, "Hearings..." [1974]). In fact, two years later, in 1976, criticisms similar to those discussed above were still being voiced. While the organization for handling energy data was better established by then, the analytical results were subject to the same attacks on credibility. Therefore, it was the attitude of many that openness had to be legislated and that relying on Administration assurances was no longer sufficient.*

*A clear instance of fears about Executive Branch pressure on the Energy Information Office can be seen in the discredit to which the Ford stripmining veto was subjected in 1975 (U.S. Congress, "Hearings..." [March 3 and 8,1976$])$. Investigative reporters and other concerned citizens charged that the facts on which President Ford based his controversial veto were either fabricated or "massaged" to fit the case; indeed, they claimed that some of the facts had been produced after the veto, in order to support and legitimize the decision. Whether or not these charges were substantiated, the fear that analysis was being altered in order to fit Administration policy goals was an extremely strong one. 
In early 1976 the GAO made a series of suggestions to Congress about the ways in which the energy data collection and analysis functions could be insulated from policy functions. Some of these included:

- "Do not provide the data agency with any regulatory or policy functions."

- "Stipulate by specific legislative provisions the responsibilities of the energy data agency emphasizing its independence, objectivity, and credibility as a source of energy data. In this regard, provide through legislative history the intent of the Congress that the head of the data agency independently speak of all matters relative to energy data, including testimony before the Congress."

- "Provide for close Congressional monitoring and oversight of the data agency's activities, including calling for the exercise of GAO's new responsibilities under the Energy Policy and Conservation Act to verify energy data." (U.S. Congress, Hearings..." [Aprit 1976].

The suggestion was that these objectives should be accomplished through statutory or other legislated provision.

While the fear of data manipulation might have been strong in any statistical setting, it was made even stronger due to the use of complex integrated modeling techniques, such as those used in the 1974 Project Independence Evaluation System (PIES). In dealing with this issue, Senator Floyd Haskell in 1976 called for both internal (i.e. governimental) and external (i.e. institutional, university) model assessment activities (U.S. Congress, "Hearings..." [March 3 and 8, 1976]). His argument was that if it is true that the use of different models containing differing methodologies and assumptions leads to different conclusions about the impacts of energy policy actions, then it is the assumptions and methodologies which need to be understood most clearly.*

*In fact, he recormended comparing the results of several modeling techniques focused on the same issue in order to identify congruences, 


\section{$A-12$}

\subsection{Issues in Energy Policy}

A third major component of the dissatisfaction surrounding the government's handling of energy information and data concerned policy ostensibly developed on the basis of the analysis of government energy information. While debates on the appropriateness or desirability of any particular course of action are the essence of policy formulation, the character of this particular debate was somewhat different, since not only the substance but the underpinnings of the policies were being challenged.

The major points were the following:

- As in the analytical process, there was a fear that the energy industry was dictating the policies that were to be enacted, and that the Administration was implementing those policies regardless of the results of its own analyses;

- there was a great deal of dissatisfaction about lack of consideration of the impact of policy on the consumer, and lack of consumer and citizen participation in general in the policy formation process; and

0 there was an apparent conflict inherent in the fact that the FEA in 1976 was in a sense promoting the same industry that it was supposcd to be regulating.

(footrote continued from previous page)

\footnotetext{
*rather than differences. If similar forecasts existed in spite of methodological variations, then the given results might be construed to be more accurate. In Senator Haskell's words: "If uniformity in certain types of energy information will facilitate the policy process, in other areas we should be seeking the diversity which arises from a number of independent assessments of inforulation. The role of the federal government should be both that of an analyzer and a provider of basic data. The sophisticated calculations and models which use basic energy information to compute the consequences or impacts of policy options should be carried out in several independent and technically qualified centers of expertise. This may lead to differing estimates of the economic impact of energy policies or to differing estimates of domestic energy reserves, because different assumptions and methodologies are employed. In this case we should discuss those assumptions and methodologies explicitly and learn from the differences. It may be that we can truly evaluate assessments of this sort only by looking for a convergence of a number of independent estimates. Where judgment is involved in dealing with energy information, the federal government should make the basic data available and encourage independent efforts to analyze this information. The creation of an institution and the procedures to open up access to energy information is a primary goal of the Energy Information Act and my amendment to it" (U.S. Congress, "Hearings..." [March 3 and 8, 1976]).
} 
Again, specific instances of these charges are numerous. For example, there is evidence in the literature that at least some Americans felt that government and big business were conspiring together to implement programs that would not necessarily be of benefit to the general public.* others were more concerned about the consumer per se, and the general lack of públic involvement. Ken Bossong, for example, of the Center for Science in the Public Interest, maintained that even legislated consumer mandates present in the FEA Act of 1974 were being ignored by the Administration in its energy deliberations (U.S. Congress, "Hearings..." [April 1976]).**

\footnotetext{
*Martin Lobel of the Citizens' Energy Platform said the following: ":. Most energy planning is still being done by the major oil companies behind closed doors with the administration. Public access to decision makers and public involvement in decision making has been a big PR confidence game. There was a lot of hoopla about public hearings around the country on Project Independence, yet, the plan was released before the transcripts of most of these hearings could even reach Washington, let alone be considered by the FEA or the White House. The same was not true with the major oil company input-that was ready and welcomed. The FEA has admitted that it conferred privately with the American Petroleum Institute before sending out a congressionally mandated questionnaire on domestic oil reserves and had deleted 11 questions at. the API's suggestion. No public input was sought in designing this form and not surprisingly the deletions made at the API's "suggestion" eliminated almost all the relevant data" (Congressional Quarterly Almanac [1976]).
}

**Ken Bossong: "While possessing an extensive public information office operation, FEA has consistently failed to alert the public to pending policy decisions early enough to give the public an opportunity to participate in their formulation. The opportunities for public participation have only come in the final stages of decision making such as the statutorily mandated proforma public hearings and Federal Register comments. It has proven to be virtually impossible for the public to have any impact upon FEA's energy. planning when the public input is so restricted.

This very limited participation is best reflected in the consumer impact analyses which section 18(a) of the FEA Act clearly specifies must accompany al1 major FEA regulatory and other actions. In the 2 years since FEA has been in existence, the agency has never prepared a satisfactory consumer impact analysis. This absence can perhaps be best seen in the FEA's 1974 "Project Independence" and the 1976 "National Energy Outlook" reports as well as in its entitlements program and its many oil-pricing decisions including the most recent residual fuel oil decontrol action. In spite of repeated requests from individuals, national and local consumer groups, and its own Consumer Affairs Special Impacts Advisory Committee, the FEA has consistently neglected to provide satisfactory consumer impact studies" (U.S. Congress, "Hearings..." [April 1976]). 
Again, this trend was viewed as a deficiency not in the analysis of the data itsel $f$, but in the policy formation process based on that analysis.

The third point of contention, concerning conflicting roles being carried out within a single agency, found proponents in at least three senators in 1976--Percy, Leahy and Chiles. These gentlemen argued at Congressional hearings that the FEA promoted the same industry that it regulated (U.S. Congress, "Hearings..." [Apri] 1976]). Their feeling was that if the role of the FEA was to represent oil interests, and they thought it was, then that same agency couldn't possibly be expected to regulate the industry in a just manner. There was also a perceived conflict between FEA's role as a promoter of deregulation and its responsibility for the legislative continuation of price controls. Any policy which that agency proposed, and indeed any analyses which it produced, were suspect, in view of the conflicting jobs that it was expected to perform.*

\subsection{Concerns About Computer Model ing}

One further issue concerned the role of analytical models in government energy planning. In its 1977 Annual Report the Energy Information Administration (1978a) defined modeling as "organizing available information, guided by informed judgment, to provide insights." In EIA's view, modeling fills the gap that occurs between data collection and validation on the one hand, and forecasting and

*As Joseph Fisher, of Resources for the Future put it, "Agencies charged with complicated and difficult and sensitive responsibilities, like rationing, or allocation or price controls, simply don't do well at objective, careful, balanced appraisal of what is going on" (U.S. Congress, "Hearings..." [1974]). 
analysis on the other. The key to the difficulty of accepting modeling as an objective, scientific means of decision making lies in the terms "judgement" and "insight." In his book Energy Planning and Policy Tom Teitenberg (1976) argues that it is precisely. because of the need for judgement and insight in the forecasting of energy trends that tension and distrust exist between decision makers (i.e. the members of Congress and the public) and modelers (in this instance, FEA, now EIA). Any time a modeler makes an analytical assumption, or makes a judgement about treatment of variables, a decision maker's opportunity to make a choice is reduced. Since judgement has been the traditional sphere of the decision maker, it is Teitenberg's theory that even with other issues more or less resolved, tension will exist between these participants.

The review of the literature indicates that some such concerns may indeed have existed, particularly when PIES was first released. As the computer modeling systems became more complex, and were thus readily comprehensible to fewer and only more highly trained people, the națure of the analytical process became more remote from the public's understanding. This, coupled with fears about Administration or industry tampering, led to a feeling that biases in computer models might be too deeply obscured to be detected. The models, purporting to be objective and factual, might not in fact be so.

This is not to imply however, that all comments concerning models were critical. For example PIES was widely praised as a good first attempt, even while flaws were noted. In its 1975 review of the model GAO stated:

"LAO believes that the 1974 Project Independence Evaluation is a valuable attempt to provide an integrated framework for evaluating energy policy. Under severe time constraints, the Federal Energy Administration developed an innovative framework for analyzing the complex and interdependent sectors of the U.S. energy system" (U.S. General Accounting Office [1975]). 


\section{A-16}

While GAO noted many problems with the system, they felt that FEA was aware of the limitations of PIES and was working toward improvements. However, GAO (1976) also stated that they felt FEA "should give highest priority . . . to development of complete documentation for the system." Reviewers from the MIT Energy Laboratory Policy Study Group (1975) and from the Battelle Columbus Laboratories (1975) cited PIES as a "critical step" in the creation of an adequate information base and as "a point of departure for. . promoting a more rational and less wasteful approach . - . to energy resources"; other scholarly evaluations of the system contained similar statements.* While these comments reflect a positive attitude towards the potential role of modeling activities in energy policy formation, they also show support for serious efforts toward improved and documented systems, and credible results.

We have seen, therefore, that the entire process of energy data collection and analysis was subject to criticism and skepticism during the mid-70s, not only because of suspicion of Administration intent and industry lobbying, but also because of fundamental weaknesses in the composition of the data base proper. However, one issue on which there was literally no disagreement was the general need for better energy data organization and manipulation: According to a GAO statement made in 1976, there were 261 separate energy-related programs being administered by 44 federal agencies and bureaus (U.S. Congress, "Hearings..." [May 3, 1976]). The FEA, ERDA, NSF and Bureau of the Census accounted for

*A reviewer from the University of New Mexico indicated that "the progress which the FEA has made in refining the PIES since the Project Independence Report gives every reason for optimism in terms of the potential of their approach in serving as a useful tool for analyzing policy options for the United States in its efforts to deal with an uncertain energy future" (Landsberg [1977]). 


\section{A-17}

one-third of those, with the federal government operating 98 separate computerized data bases containing energy-related information. This was clearly too fragmented, and undoubtedly led to duplication and an increased reporting burden on companies. Again it is important to note that this was not an argument against the concept of computer modeling. Rather, the purpose of the process was to look for ways to improve the modeling capabilities of the government, first by better in-house methodology, and second by constructive evaluation efforts.* In the following section the legislative initiatives to achieve these objectives will be considered.

\section{Legislation Concerning Energy Information}

\subsection{Early Efforts}

Congress, through a series of energy bills, asked the energy agencies in the federal government to implement a strategy for public access and model assessment which had never been tried before. In response, the government has been grappling in an increasingly direct way with achieving public access to energy information and analytical tools. Below, the steps in this legislative process are examined.

In April of 1973, Senator Jackson of the influential Senate Committee on Interior and Insular Affairs asked the GAO to perform a feasibility study on the formation of an energy data bank which would sludy both supply and demand of various energy resources (U.S. Congress, "Hearings..." [1974]). Jackson wanted this data bank to be subject to an

*Laurence Moss of the FEA Environmental Advisory Committee testified that his aim was to see more ambitious modeling efforts undertaken as a means of improving the basis for decisionmaking in the U.S. (U.S. Congress, "Hearings..." [April 1976]). 


\section{A-18}

independent input and verification process, and asked if it could profitably be placed in the Executive Branch of the government. The GAO's study, which came out early the next spring concluded that such an energy bank would be feasible within the Executive Branch, but would need to be established through a legislative procedure. Moreover, GAO indicated that it would probably take several years to develop the bank to the point of real competence (U.S. Congress, "Hearings..." [1974]). Concurrently, in the spring of 1973, the Executive Branch was considering the energy information problem. Dismantling the Office of Emergency Preparedness, President Nixon established by Executive Order a National Energy Office within the Executive Office of the President. In addition, an Office of Energy Data and Analysis was established as a part of the Department of the Interior, in response to a 1973 Nixon "energy message."

In October of 1973, as a result of the Egyptian-Israeli war in the Mid-East, the Arab nations imposed an embargo on oil exported to the United States and other nations supporting Israel. The embargo ended in March, but the associated higher prices remained in force, bringing the nation's dependency on foreign oil into virtually every American's conscious awareness. In November of 1973, while the embargo was in full swing, President Nixon galvanized his energy staff into action with a highly publicized speech proclaiming as a goal the energy "independence" of the United States by the year 1980. In addition, he issued an Executive Order that established the Federal Energy Office (FEO) within the Office of the President as an interim measure pending the implementation of the Federal Energy Administration Act by Congress (U.S. Congress, "Hearings..." [1974]). This legislation, signed in May of 
1974, consolidated the energy information offices, moving the FEO and the Office of Energy Data and Analysis to the new FEA, (U.S. Congress, P.L. 93-275 [May 1974]).

The FEA Act made a start at addressing some of the access and information concerns which were discussed above, though not to the extent of later laws. In the "Functions and Purposes" section of the Act, mention is made of involving state and local governments, as well as business, labor, and consumer interests, in the work of the Administration. Another section details the GAO's role in monitoring all activities of the FEA. Finally, Section 14 (a) reads as follows: "The Administrator shall:make public, on a continuing basis, any statistical. and economic analyses, data, information, and whatever reports' and summaries are necessary to keep the public fully and currently informed as to the nature, extent, and projected duration of shortages of energy supplies, the impact of such shortages, and the steps being taken to minimize such impacts" (U.S. Congress, P.L. 93-275 [May 1974]). Other 1 anguage regarded release of industry data and the participation of advisory committees in FEA operations. One month later, in June of 1974, the Energy Supply and Environmental Coordination Act was signed, which essentially strengthened the enforcement of reporting requirements to the FEA by energy producers and users (U.S. Congress., P.L. 93-319 [June 1974]).

However, while these bills were first steps towards better information collection and dissemination, their provisions did not really address the complicated access issues which became evident with the publication of the Project Independence Report in November of 1974 (Federal Energy Administration [1974]). This report summarized the 
results of the computer modeling effort which had been undertaken by the President's energy staff in the previous six months, an unprecedented effort in terms of scope and complexity. While nearly all reviewers agreed that the system, and indeed modeling and forecasting in general, were important to the understanding of energy/economic trends in the U.S., dissatisfaction with the extent to which assumptions could be identified and the extent to which the entire process was documented, was also widespread (see reviews by GAO [1975], M.I.T. Energy Laboratory Policy Study Group (1975), and Battelle (1975). Thus the general fears of Administration manipulation of data for policy goals, and the other concerns discussed above, were perhaps heightened rather than alleviated by the PIES report.

The energy information issue continued to be debated and many energy-related bills were submitted, considered, and enacted throughout the next two years. The Energy Policy and Conservation Act of 1975 (U.S. Congress, P.L. 94-163 [December 17, 1975]) further strengthened the FEA's information-gathering capabilities, and authorized GAO accounting audits into energy-related corporate finances. In addition, in December of 1975 an Interagency Council on Energy Information was formed, with representatives from FEA, the Federal Power Commission, the Department of the Interior, the Energy Research and Development Administration, GAO, . and the Office of Management and Budget. The purpose of this council was to provide for better coordination and quality of energy information gathering activities, and it had three basic tasks:

1) to standardize the terminology and classification used by various energy parties in order to allow for study results to be more easily compared;

2) to register all energy data collected in order to identify and eliminate duplication of effort; and 
3) to analyze future requirements for information--that is, to identify gaps in the existing data network (U.S. Congress, "Hearings..." [May 3, 1976]).

\subsection{The Energy Conservation and Production Act}

However, the most direct tool for providing access not only to government and industry data and reports, but also to the methodology and analysis behind those reports, was provided in the Energy Conservation and Production Act of 1976 (U.S. Congress, P.L. 94-385 [August 14, 1976]). This piece of legislation addressed itself directly to the problems posed by computer modeling and to increased access in general. It did this by means of two major amendments to the FEA Act of 1974, the first concerning PIES and the second establishing an Office of Energy Information and Analysis.

The first amendment, which dealt with PIES, was an addition provided by the House Committee on Interstate and Foreign Commerce. It contained three major provisions:

1) that all structural, parametric and operational documentation of the model must be submitted to Congress;

2) that representatives of Congressional committees must be provided with access to the model; and

3) that members of the public be permitted access to the model on the FEA computer system, on reasonable terms.

The reasoning behind such unprecedented language can be found in the Committec's report on the bill (U.S. Congress [May 10, 1976]). As the excerpt below taken from that report indicates, the Committee's concern was that public access to the model should be as broad as possible. Because the intent of this legislation is as critical to further interpretation of access requirements as the letter of the law itself, this section of the Committee report is reproduced below in full. 
"The Office of Energy Policy and Analysis has been assigned principal responsibilities for the development of the Project Independence Evaluation System (PIES) computer model. This model has played a major role in the evolution of the policies of the Federal Energy Administration and, indeed, of the Congress in dealing with the energy problems which confront us. The Committee is persuaded that such an analytical tool can indeed serve a highly useful purpose, but is concerned that the model should be given searching and independent review and that it should be made accessible to all segments of the public which desire access to it. The Committee has recently contracted for the services of a group of independent consultants to prepare an evaluation and review of the PIES model. This evaluation will be made available to the Congress, and hearings will be held on this matter after this evaluation is completed this summer.

In keeping with a perceived need for public access, the Committee wrote into the legislation a specific requirement that the Administrator provide full descriptive documentation of the computer model by September 1 of this year and operating documentation by January 1, 1977. This was required not only because such documentation is necessary in order to allow independent access to the model, but also because the Committee is aware that a number of individuals involved in the construction of this model may soon leave, making it difficult for their successors to accurately understand and operate the model.

The Committee also required the Administrator to provide ready access to the PIES model to representatives of Congressional Committees. While the costs of any such access must be borne by the Administration, it is believed that open access to Members and to duly accredited employees of Congressional committees will not result in extensive additional costs or burdens. If the Committee's expectations in this regard prove 111 -founded, the Committee is prepared to consider remedial legislation.

The Cormittee also concluded that it would be appropriate and desirable for the Administration to make its model accessible to members of the public as well, but wishes to make it clear that any such access would be conditioned upon proper terms and conditions imposed by the Administration to insure that its other official functions are not impeded. Costs of such access, including both computer time and costs of providing staff to assist members of the public using the model, would be borne entirely by those obtaining access.

Some concern was expressed that this broadened public access to the PIES model might in some manner encourage access by unauthorized persons to proprietary information. While it is true that FEA does have access to such information, the legislation requires only that the model itself be accessible to the public--not that the data base which the model was established to deal with should be accessible. The Committee intends that the confidentiality of any such information will not be endangered by this legislation.

It is the purpose of the Committee in adopting these additional constraints to insure that the model is given thorough and adequate public review. The Committee notes the intention of the 
Administration continually to update the model and annually to update its National Energy Outlook. We commend this activity as a useful and, indeed, essential element in the effort to maintain the utility of this model as an element in the development of a national energy policy. It is the Committee's expectation that the annual reviews and revision of the model will be conducted openly and that members of the public will be provided an opportunity to review decisions which lead to changes in the model structure, assumptions and scenarios tested. The Committee is reluctant to write specific, rigid, technical and procedural requirements since it is very much aware that excessive rigidity may inhibit efficient and timely results. The Committee does, however, expect the Administration to make every effort to insure that this process continues in an open manner" (U.S. Congress [May 10, 1976]).

Thus the Committee's concerns revolved around independent review of the model, future usability of the analytical tools, and broad public access to the model in general. This interpretation of the access issue was a.lso referred to in a 1978 report prepared by the Logistics Management Institute (LMI) for DOE, which concluded after talking with staff members of the same House Committee that drafted the ECPA Amendment that the broadest interpretation of access was to be implied by the legislation (U.S. Congress, P.L. 89-487 [July 4, 1966]).

The second major set of amendments contained in the ECPA established the Office of Energy Information and Analysis (OEI\&A), which was subsequently to be named the Energy Information Administration (EIA). This amendment was not a part of the bill as it went to the committees, but instead was added from the Senate floor by Senator Floyd Haskell. While it was adopted by the narrow margin of only one vote (46-45), the amendment was retained by the Conference Committee, who stated the following:

"The purpose of the Office of Energy Information and Analysis amendments is to insulate the energy data-gathering and analysis functions of the FEA from the policy making responsibilities of the agency" (U.S. Congress, [August 4, 1976]). 
The purpose as contained within the Act itself was to "assure the availability of adequate, comparable, accurate, and credible energy information to the FEA, to other government agencies responsible for energy-related policy decisions, to the Congress, and to the public." To quote Senator Haskell from an earlier attempt to set up such an administration:

"Where judgement is involved in dealing with energy information, the Federal government should make the basic data available and encourage independent efforts to analyze this information. The creation of an institution and the procedures to open up access to energy information is a primary goal. . ." (U.S. Congress, "Hearings..." [March 3 and 8, 1976]).

Thus, both credibility and accessibility were priority concerns.

The most important sections creating the OEI\&A established a comprehensive Energy Information System, guaranteed that this Office would have sophisticated analytical capabilities, coordinated energy information collection activities, provided for adequate documentation for all reports prepared including validation audits, provided for Congressional access to all energy information in the possession of the Office, and finally, called for outside review of the procedures and methodology employed by the OEI\&A (U.S. Congress, P.L. 94-385 [August 14, 1976]). This review was to be accomplished by a Professional Audit Review Team (PART) composed of members of other Federal agencies and chaired by the GAO. The mandate of PART was to investigate all aspects of the Office's performance and activities and to report once annually to the President and to Congress. The PART review function is still intact at this time, and two such annual reports have been produced.

It is evident that the Haskell amendment, and thus the EPCA of 1976 , was a sweeping attempt to address many of the concerns discussed above, 
including adequacy of the energy information data base, credibility of the analytical functions of the agency, insulation from policymaking activities, and thorough review and oversight by other agencies and by the public. A question exists about whether access to the agency's information was not already guaranteed by the Freedom of Information Act of 1966 and its amendments, but an examination of this subject by LMI (1978) led them to the following conclusions:

"Even without an EPCA, the Freedom of Information Act (FOIA) would enable the public to obtain much of the PIES information that they might require. Nonetheless, the EPCA does enlarge the public's rights to such information and services beyond what they might have ob tained under the FOIA."

\subsection{The DOE Organization Act and Recent Events}

In spite of specific legislative protection for access and review, criticisms of the federal government's energy information organization were not quelled. In August of 1977 the entire organizational structure of:energy administration was changed with the passage of the Department of Energy Organization A.Ct (DOE ACt) (U.S. Congress, P.L. 95-91 [August $4,1977])$. This legislation, which received strong support from both houses of Congress, created a new, Cabinet-level Department of Energy in which the Administration's energy affairs would be consolidated. According to a Senate Committee on Governmental Affairs report of May 1977 , in which the DOE bill was reported favorably, over 100 separate energy data programs were to be folded into the new DOE (U.S. Congress [May 14, 1977]). While Many considerations other than those related to data and information were present in this report, the Committee did concern itself with the need for better data organization. For example, the report claimed that the FEA, ERDA, and the Department of Interior had published conflicting reports, interpretations, and forecasts concerning 
the nation's energy situation. At hearings accompanying the proposed legislation, similar refrains were heard: dissatisfaction with fragmentation of data collection efforts; non-usability of information; lack of public participation in energy decisions; lack of access to PIES and other information; and a need for more public accountability (U.S. Congress, "Hearings..." [March, Apri7 1975]).

The Senate Committee Report, however, emphasized that it intended to ameliorate these difficulties in the new department. The report stressed insulation of the new Energy Information Administration (EIA) from policy affairs, production of independently verified data and credible reports. For example: "The Committee strongly endorses this separation and wishes to explicitly incorporate in DOE those provisions which require that the independence of data gathering and analysis from policy formulation be reflected in the organization of the Department" (U.S. Congress [May 14, 1977]). The House Commitiee on Government Operations addressed the access issue more directly in their report on the DOE Act:

"One of the most pervasive problems which various citizens groups have seen with the energy situation has been their inability to obtain accurate energy information: . . .H.R. 6804 establishes as one of its purposes encouraging public participation in the development and enforcement of a national energy program. To assist in achieving this purpose, the Energy Information Administration was established to independently collect, analyze and disseminate energy information. In performing these functions, the Administrator of the Energy Information Administration is not subject to the supervision of any officer or employee of the Department of Energy. This administration should provide the public with pertinent energy information" (U.S. Congress [May 16, 1977]).

Finally, the Conference Committee, whose final version of the DOE bill was accepted overwhelmingly by Congress (353-27 in the House; 76-14 in the Senate), also emphasized in their report that the new EIA would specifically be expected to accept all responsibility for public access 
and review which had been required by the EPCA of 1976 (U.S. Congress [July 26, 1977]): While the DOE Act consolidated many activities, the EIA was to remain as independent as possible, and to remain as open to the public as existing disclosure laws would allow.

In August of 1977 the DOE bill became la's. In December of that same year the first annual Professional Audit Review Team (1977) review was published. PART had been in existence nine months at that time, and was only considering OEI\&A's performance through October of 1977. Therefore it was not surprising that the report contained many of the sarine complaints that had been voiced previously, and stated that little progress had been made by OEI\&A in meeting legislated requirements. Specifics cited included questions about accuracy of data, adequacy of verification, credibility; insulation from policy making, and lack of model documentation. The latter point was considered critical, since documentation of model assumptions and methodology is a key factor in model access. PART stated that access to PIES was blocked due to changes in assumptions without adequate notation of the facts, and they concluded the following:

"OEIA's credibility was adversely affected by a failure to make available to the public the results of all its forecasts and the source and rationale for the assumptions upon which the changes to the model were based. Moreover, OEIA failed to insure the integrity of the model by not obtaining the views of modeling and energy experts outside of FEA regarding the model's assumptions and the appropriateness of the changes" (Professional Audit Review Team [1977]).

In the ensuing two years, much time and money has been spent considering the access issue, both within and outside of government. While recent energy legislation has not addressed access to energy models directly, the ongoing use of models as tools for formulating energy 
policy has led to increased attention to issues of model development and credibility, documentation, and assessment. For example, the Energy Information Administraton has contracted the Argonne National Laboratory's National Energy Software Center to archive PIES and other energy models, as a means of making them available for public use. In addition, EIA transferred PIES (now called MEFS) to the Texas Energy and Natural Resources Advisory Council, and has issued internal interim documentation standards for EIA-sponsored efforts. The very broad interpretation of "access" which Congress intended has challenged the modeling community, and concerns over data, analysis, policy, and modeling have not yet been totally satisfied. However, objectives of credible energy information are being pursued, and will undoubtedly continue to be so in the future. For example, the second annual PART review concluded,

". . PART believes that EIA operated independent of the energy policy function, that it was organized and managed in a more professional manner than its predecessor. . . Moreover, recent actions... indicate that EIA is making progress toward improving the quality and reliability of Federal energy data and analysis activities. However, these are only the first steps and much more needs to be done before EIA fulfills its Congressionally mandated charter as the principal source of adequate, accurate, comparable, and coordinated energy information within the Government" (Professional Audit Review Team [1979]). 
B-1

APPENDIX B

A Review of Model Access Activities at Various Government Agencies 
Appendix B

\section{A Review of Model Access Activities at Various Government Agencies}

As a means of providing perspective on model access efforts undertaken at the Energy Information Administration, an informal survey of activities at other agencies was made by members of the MIT Energy Model Analysis Program. Conversations were held with members of analytical organizations, and the literature was consulted, notably Logistics Management Institute's (1978) recent "Recomendations for PIES Access" report.

The results of this survey have indicated that formal access to and evaluation of computer model is not an institutionalized process. Perceptions vary widely between organizations as to the appropriate forms and levels of outside review of computer models and documentation. While the EIA is under a legislated mandate to make public all aspects of the PIES documentation, including all code and support manuals, another agency (DOT) refuses to release the source code for its UTPS model on grounds of needing to maintain the integrity of the system (Logistics Management Institute [1978]). While one group funds thorough model assessment of its models, another feels that the only evaluation worth supporting is that which is aimed at actually correcting and improving existing programs. Attitudes towards fees for model access vary widely also, ranging from no fee at all to several thousand dollars for the lease of a system.

To generalize, there appear to be three basic approaches to providing access to models: 


\section{B-3}

1. Provide limited access only when requested,

2. Provide archiving services for the use of the general public,

3. Provide in depth conceptual assistance with the operation of a model.

An example of the first approach to modeling may be seen at the Transportation Systems Center of the Department of Transportation. At that organization, documentation for specific models is made available upon request, but work is more often presented to peers through seminars or informal information exchanges. While limited access may be achieved, the major purpose for these discussions with other transportation experts is: to determine better means of modeling, and improve existing. systems.

Two organizations participate in the second $k$ ind of access activity: the National Energy Software Center (NESC) at the Argonne National Laboratory, utilized by the Nuclear Regulatory Commission and EIA, and NASA's Computer Software and Management Information Center (COSMIC). These agencies are similar in that they test, operate, and run sample problems on programs before supplying them on tape to requestors. NESC currently maintains approximately 900 programs, while the number at COSMIC is closer to 1600. All available codes and documentation are made available to the public, and NESC will provide technical operating assistance to users over the telephone when necessary. However, conceptual assistance with programs is not offered by the Software Centers, and must be sought from the model developer.

The third kind of access, that which would provide conceptual assistance with model implementation, has little precedent in the government to date. The Energy Information Administration is unique in that its models were singled out by Congress for an access mandate; as Appendix A discusses, Congress stated that the PIES models should be 
available to members of the public on the EIA's own computer system (U.S. Congress, P.L. 94-385 [August 14, 1976]). This definition of access clearly exceeds those suggested above. However, LMI (1978) has reported that some conceptual/programming assistance is made available by NASA to users of a particular model (NASTRAN) through the contracting of outside services.

Below are presented the results of interviews with representatives of two government agencies. These summaries have been included for comparative purposes, and as a means of providing further detail. Bureau of Labor Statistics

Models developed by the Bureau of Labor Statistics (BLS) are used primarily to determine the economic outlook and employment projections produced by that agency. While gross figures are released to the public at large, more detailed madel results are provided to and used by the EPA, DOE, other federal and state agencies, universities, and private firms.

\section{Access}

In terms of access, the BLS models are considered to be fully public. All outside requests for information are answered, either at no charge, or on a cost-reimbursement basis, depending on the amount of time required. Most information requests are in the form of specific questions about labor statistics, which BLS can answer within a day or: two. The staff will perform analytical work with the models on request, but have very little occasion to do so; most requestors are not interested in specifying scenarios.

While the office maintains four terminals, they are for the use of in-house staff only, and the computer facility proper is located at the 
NIH. Outsiders are not permitted the use of BLS terminals. However, the model programs, documentation, and data bases are provided to any member of the public upon request at cost. Code is provided on tape. The BLS provides code in the format in which it is used in-house; it is up to the requestor to find compatible computer equipment for running the model.

BLS personnel give technical assistance only by telephone to those users who request it. It is common for a new user to encounter some difficulty in getting the model operational at his home site, and the BLS provides "trouble-shooting" assistance by telephone. In addition, agency staff will answer conceptual questions by telephone, if they are not too complex in nature. Most often, these questions concern whether or not a particular factor was considered in the development of a model; such questions are answered and the reasoning is explained. The BLS does not provide any kind of training in the general use of models, however, or in the application of any particular model.

The answering of questions, both operational and conceptual, takes up part of the time of one staff person. However, this time is required on an erratic basis, and is therefore difficult to budget accurately. Questions tend to come in a group after the publication of a new projection.

\section{Evaluation}

The BLS does not have any institutionalized process for model evaluation. Their major macro model was developed at Harvard, and was the result of an interagency effort. At that time, the model was subjected to the normal peer review process and evaluative feedback was received from sume of the other agencies invulved, including the Department of Commerce. BLS model building has been an ongoing process 
for several years; when the activity was initiated, an interagency task force set down a research program and continued to be active for a half a dozen years in developing the BLS projection system. This approach served as a means of involving top-level people from both with in and outside of the government in building the BLS models. At this point, however, the BLS is not interagency in nature, but is a part of the Department of Labor, and no formal outside assessments are undertaken. Instead, model (s) are reviewed in-house, and the modelers make changes to the system on their own initiative, or in accordance with specific information desired. On occasion, technical advice from academic institutions is sought and contracted for on a consulting basis.

Some outside review is provided by two advisory committees, one of which is composed of business economists, and the other of labor economists. These comittees meet separately about 3 times a year on a workshop format, and model methodologies and results are discussed. However, comments are directed more toward the research program being conducted than toward technical format of the model. Thus, assessments, as they are currently perceived, are really not carried out on BLS models.

\section{Bureau of Economic Analysis}

The Bureau of Economic Analysis (BEA) has developed and maintains two econometric models. The first provides short-term analysis by quarter, and makes projections for 6 to 8 quarters ahead. The second model, a long-term system, was not completed at the date of this research; therefore, the following information on access and evaluation pertains to BEA's practice with the short-term model. 


\section{Access}

The BEA provides access to its short-term model to users from within the Federal government only. Access is denied to the general public at least in part because of a concern that results produced by an outside user will be ascribed incorrectly to the BEA. However, access to government users is provided in several ways. Thirty or forty government agencies are on a mailing list which provides for mailings of printout and projections. In order to be inciuded on this list, the recipient agency must use the information on a regular basis and must request the data in writing. In addition, interactive time-sharing capabilities are being developed on an experimental basis, so that a few specific high-volume users can make their own model runs. For other agencies, the BEA is willing to run scenarios or develop specific model variations, however only a very few departments (the Department of the Treasury and the. Council of Economic Advisers) ever request the service.

\section{Evaluation}

The BEA does not at present maintain any form of regular third-party evaluation. There is no formal advisory committee to oversee model development, application, or evaluation. However, representatives from the BEA have indicated that user evaluation is a constant ongoing process at the agency. For example, meetings are held with economists from other government agencies and with model users, and ideas suggested by those persons are frequently tested and implemented by model builders at the BEA. In addition, BEA model builders engage in internal research on basic parts of the model, discuss these ideas with users, and in general keep up with developments in the modeling profession. The BEA places a great deal of emphasis on these informal information exchanges since they 


$$
\text { B-8 }
$$

consider their users to be relatively sophisticated.

The BEA has indicated that they would not object to outside assessment of their models, and that they have participated in some model and forecasting comparisons. In addition, they have considered contracting non-BEA model builders to examine certain model aspects in which in-house expertise is limited. 
C-1

APPENDIX C

A Survey of non-EIA Activities Relating to

Policy Model Documentation, Access, and Evaluation 


\section{C-2}

\section{National Science Foundation (NSF) Activities}

The NSF has supported a number of model evaluations as well as research on influential policy models which have helped shape current practice and understanding of the model assessment process. Although not specifically concerned with energy models, an oft-cited NSF-sponsored study by Fromm, Hamilton, and Hamilton (1974) surveyed modelers and model sponsors on model characteristics, documentation, and actual use in supporting policy research. The questionnaire for project director obtained information on general description of model, model development, cost of development, planning factors and data, supporting facilities, documentation, model utilization, model assessment, and opinions concerning various policies to facilitate model development and application. The questionnaire for agency sponsors included questions about agency rationale for supporting the model development, cost and funding, model utilization, model assessment, and opinions concerning policies to influence model development and application. The study is often cited for its evidence regarding poor documentation of models, and relatively low utilization. While not detailed with respect to opinions about approaches to validation and verification, the survey did include questions on opinions concerning a model clearing house, standardized routines and procedures, federal standards and procedures for validating and evaluating models, and validation review boards. In general modelers and model sponsors tended to have complementary views, exhibiting some support for the idea of a model clearing house and for standardizing computer routines and algorithms, and opposing federal standards and review boards for validation, with review boards being slightly favored over standards. While the survey produced much useful information, it 
was not really focused on obtaining opinions on how to improve the utility of policy models, and provided no scope for allowing respondents to indicate their views as to what would constitute good practice and procedures for policy model validation and verification.

The NSF, together with the Russell Sage Foundation, also supported another important research effort, the study by Greenberger et al. (1976) on models in policy research. While not explicitly concerned with energy models, Greenberger et al. considered the role of modeling in policy research and, through case studies, the circumstances likely to influence the success or failure of such modeling efforts. Case studies were developed for models employing different methodologies and a detailed analysis of the New York City-Rand Institute as a policy research organization was undertaken. Based upon their analysis and case studies, Greenberger and his colleages arrived at rather harsh conclusions concerning the present state of policy modeling, and the reasons for low credibility of such models. Thus:

Professional standards for model building are nonexistent. The documentation of models and source data is in an unbelievably primitive state. This goes even (and sometimes especially) for models actively consulted by policy makers. Poor documentation makes it next to impossible for anyone but the modeler to reproduce the modeling results and probe the effects of changes to the model. Sometimes a model is kept proprietary by its builder for commercial reasons. The customer is allowed to see only the results, not the assumptions (Greenberger et al. [1976], p. 338).

To rectify this situation, Greenberger et al. believe that a new professional activity needs to evolve.

What we do propose, however, is the development of a new breed of researcher/pragmatist--the model analyzer--a highly skilled professional and an astute practitioner of the art and science of third-party analysis. Such an analys is would be directed toward making sensitivity studies, identifying critical points, probing questionable assumptions, tracing policy conclusions, comprehending the effects of simulated policy changes, and simplifying complex models without distorting their key behavioral characteristics. 
The model analyzers would be neither model builder nor model user, but in a middle position between the two, empathetic to both (Greenberger et al: [1976], p. 339).

This proposal, the development of a professional interest in third-party assessment of policy models, is often cited as an important stimulus to the development of model assessment. However, Greenberger et al. provide little more information on how such a professional activity is likely to evolve, other than to note the problem of professional incentives. It has remained for DOE and EPRI to begin the process of stimulating model analysis and assessment research activities.

NSF has sponsored a number of model evaluation efforts, including the reviews of the first version of PIES by the MIT Energy Laboratory Policy Study Group (1975) and the Battelle Memorial Institute (1975), and a review by Brock and Nesbitt (1977) of six energy/economy models. Interest in the PIES evaluations was considerable, with the principals presenting testimony before the Joint Economic Committee (U.S. Congress, "Hearings..." [March 1975]). The Brock and Nesbitt review, which develops considerable pedagogical information relating to energy/economy modeling, has also been influential.

In addition to supporting research on models in the policy process and actual model evaluations, NSF has supported two conferences relating to model validation, including the Conference on Model Formulation, Validation, and Improvement held in Vail, CO, June 14-15, 1975 (National Bureau of Economic Research, Inc. [1975]), and the Workshop of Validation of Mathematical Models of Energy-Related Research and Development held at Texas Christian University, June 21-23, 1978 (Deeter and Hoffman [1978]). Electric Power Research Institute (EPRI) Activities

At about the same time that the Congress was legislating the PART 
into existence, EPRI began a series of activities relating to model assessment and analysis, and to improving understanding of the scope for energy policy models in the policy research process.

Perhaps the most significant of the early EPRI activities was sponsorship of the EPRI-Stanford Workshop for Considering a Forum for the Analysis of Energy Options Through the Use of Models (Stanford Institute for Energy Studies [1977]). The purpose of the workshop was to discuss and plan a forum which would provide a means for organizing studies involving modelers and model users in the analysis of selected energy problems. The activity, subsequently titled the Energy Modeling Forum (EMF) represents a most creative "invention" for organizing policy research. The activities of the EMF thus far include contributions to important energy issues including a study of the relationship between energy and the macroeconomy, a study of the issues surrounding the role of coal in the transition to new energy sources, and a study of models in electric utility planning. Additional studies are currently under way on a survey and analysis of energy demand elasticities, and a study of oil and gas exploration and production models is being conducted. The EMF has spawned a similar EPRI Forum concentrating on electric utility models, and the general style of the EMF has been adopted in an experimental "Energy Policy Forum" activity organized within the Department of Energy. The EMF studies are widely recognized as making a significant contribution in the analysis of important energy issues as well as representing a successful initiative in organizing modelers and model users in conducting policy research.

In parallel with the Forum, EPRI has also sponsored the M.I.T. Model Analysis Program, an experiment in al ternative approaches to independent 
model assessment. Independent, or third-party, model assessment was discussed at the EPRI-Stanford Workshop, and their role in relationship to the Forum activity was summarized as follows.

The panel described the role of third-party model analysis as a complement to Forum studies. The Forum must exploit the backroom concept of Forum operations, relying on the model developers to implement and translate the scenario specifications. The significant practical advantages of the procedure are achieved at the loss of the advantage of constructive independent investigation of model structure and operation. This activity supports the objectives of the Forum effort, but requires a different environment with intense inolvement of individual analysts. The contributions of third-party assessment can be pursued independently (Stanford Institute for Energy Studies [1977]).

As an outgrowth of this discussion, the M.I.T. Energy Laboratory organized the Model Analysis Program (1979) to undertake, with EPRI sponsorship, independent assessment of two important energy policy models, the Baughman-Joskcw Regionalized Electricity Model, and the Wharton Annual Energy Model. As a consequence of this study, the group identified a number of key issues in organizing and conducting policy model evaluations. EPRI has also sponsored assessments of energy models of special interest and importance to the electric power sector. These include an assessment by Charles River Associates, Inc. (1976) of models of the demand for electric energy, assessment of studies of coal supply (Gordon [1977]), and a review of the Brookhaven National Laboratory's model relating to electric utility R\&D planning (Systems Control, Inc. [1978]), and comparative assessments of natural gas supply models (Mathtech, Inc. [1977]).

\section{General Accounting Office (GAO) Activities}

The GAO has both conducted model evaluations and contributed guidelines for model validation and verification. Following publication 
of the Project Independence Report (Federal Energy Administration [1974]) and at the request of Congress, GAO (1975) prepared an evaluation of PIES based upon the M.I.T. and Battelle reviews and upon their own independent evaluation.

The GAO (1979) has proposed guidelines for model evaluation intended to increase credibility and usefulness of policy models, and to promulgate good scientific practice in policy model development and application. The GAO guidelines are closely related to the efforts of Gass (1977), emphasizing evaluation of model documentation; theoretical, data and operational validity; and verification of computer implementation. The guidelines provide an excellent discussion of issues in policy model evaluation and analysis.

\section{National Bureau of Standards (NBS) Activities}

The NBS has been involved in sponsoring research on approaches to improving policy model credibility, in developing standards for model documentation, in organizing conferences to facilitate communication among modelers, model analyzers, and model users, and in conducting policy model evaluations. With NBS sponsorship Gass (1979a) has considered the functions and structure of policy model documentation. He analyzes the policy model development process identifying thirteen distinct stages in a model's life cycle and proposes document types for each phase. Gass avoids recommending specific formats, recognizing that such detail will depend upon such factors as the purposes for which the model is intended, and need for model portability. Thus,

Depending on the scope and ultimate use of the model; some of these documents can be el iminated or combined. In any event, the user/sponsor and the model developer must conclude an agreement as to the documents produced, their content, uses and audiences: : The form of the documents can range from a few pages to detailed manuals (Gass [1979a]), pp. 34-35). 


$$
\text { C-8 }
$$

NBS has also sponsored survey of the means by which the credibility and utility of policy models may be improved. The study, conducted by Computer Analysis Corp. (CAC), presented eighteen proposals to improve model utility for evaluation and comment by 39 respondents representing universities, government agencies, profit and nonprofit organizations with particular expertise in analysis, simulation, and economics (Energy Information Administration [1979]).

In addition to conducting/sponsoring research on improving modei credibility and developing guidelines for model documentation, NBS has also sponsored workshops, including the present one, and a workshop on the Utility and Use of Large-Scale Mathematical Models (Gass, editor: [1979b]), and is presently conducting an assessment of the PIES oil and gas submodel to be discussed in the next section. 